\title{
A produção científica sobre o ambiente na saúde coletiva
}

\author{
Brazilian public health research \\ output related to the environment
}

Carlos Machado de Freitas ${ }^{1}$

\begin{abstract}
1 Escola Nacional de Saúde Pública, Fundação Oswaldo Cruz, Rio de Janeiro, Brasil.

Correspondência C. M. Freitas

Centro de Estudos da Saúde do Trabalhador e Ecologia Humana, Escola Nacional de Saúde Pública, Fundação Oswaldo Cruz. Av. Leopoldo Bulhões 1480, Rio de Janeiro, $R J$ 21041-210, Brasil. carlosmf@ensp.fiocruz.br
\end{abstract}

\begin{abstract}
Although there are few scientific studies on the environment in the Brazilian public health literature, there are indications of recent growth in this theme in research and graduate programs in Brazil, thus tending to consolidate the scientific output in this area. The objective of this study was to contribute to the understanding and characterization of this theme in public health, offering backing for establishing research focused on sustainability of the environment and health. We identified and analyzed the research output on the environment in the most important Brazilian scientific journals in public health (1992-2002), using as the reference Chapter 35 of Agenda 21 (science for sustainability). The results showed: research output highly concentrated in the more affluent Southeast region of the country; predominance of the biological concept of health and the biophysical concept of environment; prevalence of diagnoses versus the search for solutions; and few studies involving stakeholders' participation.
\end{abstract}

Environmental Health; Environment and Public Health; Review Literature [Publication Type]

\section{Introdução}

Ao longo do século XX, e particularmente a partir da década de 70 , se intensificam e ampliam as ações do Estado no que concerne à conservação e preservação da natureza. Até o início dos anos 70 estas ações estiveram dirigidas principalmente ao ambiente biofísico (gestão da vida selvagem, conservação do solo, poluição aquática, degradação e desertificação da terra), sendo os seres humanos considerados como a origem dos problemas 1,2 . Neste processo, a Conferência das Nações Unidas sobre o Ambiente Humano, realizada em 1972, na cidade de Estocolmo, Suécia, foi um marco. Contribuiu para a mudança das atenções centradas na noção de preservação e conservação da natureza biofísica para a noção de um ambiente global, colocando as questões ambientais no topo da agenda política nacional, regional e internacional. A esta noção articulava-se a idéia do direito dos seres humanos viverem em um ambiente de qualidade que permitisse uma vida com dignidade e bem-estar, passando a ser incluído na constituição de alguns países o reconhecimento do ambiente como um direito humano fundamental. O ponto alto deste processo foi a realização da Conferência das Nações Unidas sobre Meio Ambiente e Desenvolvimento, realizada em 1992, na cidade do Rio de Janeiro, Brasil, tendo como um de seus resultados a Agenda 21, um programa de ações para 
o século XXI que constitui um marco na questão ambiental 1,3, tendo dois capítulos de grande interesse para este trabalho.

O primeiro (capítulo 6), encontra-se na seção I, dedicada às dimensões sociais e econômicas, e reconhece a saúde ambiental como prioridade social para a promoção da saúde. O segundo (capítulo 35), encontra-se na seção IV, dedicada aos meios para implementar o desenvolvimento sustentável, reconhecendo a importância da ciência para o desenvolvimento sustentável.

Ambos os capítulos são de grande importância para a reflexão e orientação das inter-relações entre os problemas ambientais e de saúde em uma área do conhecimento como a saúde coletiva, que emerge e se consolida no Brasil no mesmo período em que o tema "ambiente" transforma-se em um problema global. Entretanto, o foco deste trabalho é norteado principalmente pelo capítulo 35, em que é reconhecido que o desenvolvimento científico tem um papel fundamental como meio para implementar o desenvolvimento sustentável, devendo-se orientar para a gestão prudente do meio ambiente e do desenvolvimento. Para que este papel possa ser cumprido, a primeira área de programas proposta neste capítulo é o fortalecimento da base científica para o manejo sustentável, em que são estabelecidos seis objetivos, sendo estes: (1) ampliar e fortalecer as capacidades e potenciais científicos em áreas relevantes para o meio ambiente e desenvolvimento; (2) formulação de políticas sobre meio ambiente e desenvolvimento baseadas no conhecimento científico, aumentando a cooperação internacional e reconhecendo as incertezas; (3) maior interação entre as ciências e a tomada de decisões, utilizando a abordagem da precaução; (4) geração de conhecimentos locais, considerando as outras escalas (nacional, regional e internacional); (5) promoção de atividades e programas interdisciplinares de pesquisa; e (6) participação popular na fixação de prioridades e nas tomadas de decisões.

Essa primeira área e seus objetivos se encontram em consonância com os da própria saúde coletiva, que, tomando como referência Paim \& Almeida Filho 4, se constitui como um campo científico interdisciplinar e um âmbito de práticas intersetoriais em que se produzem saberes e conhecimentos sobre o objeto "saúde”, como também ações por diversos agentes, especializados e "leigos", dentro e fora das instituições reconhecidas como do "setor saúde". O fortalecimento da base científica de uma ciência orientada para o desenvolvimento sustentável não pode prescindir do fortalecimento da base científica de uma ciência para a saú- de coletiva, devendo, combinadas, conformar uma ciência orientada para o desenvolvimento sustentável do ambiente e da saúde coletiva, à qual deve não só se restringir para busca de soluções para o controle e prevenção de doenças, mas também, e principalmente, para a promoção da saúde.

Existem estudos recentes, como o de Barata \& Goldbaum 5, que apontam para o aumento da pesquisa e da produção científica sobre o tema ambiente no próprio bojo de crescimento da saúde coletiva. Este se deu pelo aumento do número e ampliação de programas de pósgraduação, da constituição de grupos de pesquisa, do número de pesquisadores qualificados e da consolidação da produção científica. Estes autores 5, no estudo que realizaram sobre os bolsistas de produtividade em saúde coletiva, constataram que na distribuição das linhas de pesquisa mencionadas, "meio ambiente e desenvolvimento sustentado" aparece em terceiro lugar, com cem linhas e correspondendo a $4,44 \%$ do total. Freitas 6 , em um levantamento de teses e dissertações sobre o tema "ambiente" produzidas no Brasil entre os anos 1980 e 2000, constatou um nítido crescimento da produção no período, principalmente a partir da segunda metade da década de 90 , período que concentrou mais da metade da produção (54,0\%) de todo o período.

Embora ainda existam poucos estudos sobre a incorporação do tema ambiente na saúde coletiva, há indicações que apontam para a institucionalização desse tema nas linhas de pesquisas dos grupos de pesquisas e programas de pós-graduação, bem como na formação de pesquisadores qualificados e se consolidando na produção científica. Dada a relevância política e científica que o tema ambiente alcançou desde os anos 70, principalmente a partir da última década do século passado, torna-se importante compreender, caracterizar e apontar as tendências da incorporação dessa temática na saúde coletiva, fornecendo assim subsídios para a conformação de uma ciência orientada para o desenvolvimento sustentável do ambiente e da saúde coletiva. Objetivando contribuir para isto, realizou-se levantamento e análise da produção científica sobre o tema ambiente nas principais revistas científicas nacionais da saúde coletiva.

\section{Método}

Estudos realizados sobre a difusão do conhecimento e a produção científica na saúde coletiva revelam que os textos publicados em revis- 
tas científicas, embora não sejam os únicos produtos da pesquisa, constituem uma das principais formas de difusão 5,7,8. Assim, para este estudo estabeleceu-se como universo de análise os textos publicados em quatro revistas científicas nacionais de grande circulação, entre os anos 1992 e 2002.

Em relação às revistas científicas, foram selecionadas quatro que, além de serem criações da saúde coletiva, são as que, de acordo com estudos recentes, mais vêm publicando textos científicos 5,9. Essas revistas são: Cadernos de Saúde Pública (Cad Saúde Pública); Revista de Saúde Pública (Rev Saúde Pública); Ciência e Saúde Coletiva (Ciênc Saúde Coletiva); e Informe Epidemiológico do SUS (Inf Epidemiol SUS). As duas primeiras são as revistas científicas mais freqüentemente utilizadas, estão vinculadas a duas grandes instituições que possuem os maiores programas de pós-graduação em saúde coletiva, são indexadas em bases de dados de reconhecimento internacional para as ciências da saúde, como o MEDLINE, e representam o núcleo duro da publicação de textos científicos nacionais 5,7,9. A Ciênc Saúde Coletiva, além de pertencer à Associação Brasileira de Pós-Graduação em Saúde Coletiva (ABRASCO), representa a que se dedica à publicação científica dos grandes temas considerados relevantes para a saúde coletiva, além de artigos contendo discussão e análise do estado da arte na mesma. O Inf Epidemiol SUS, que foi publicado até 2002 pelo Centro Nacional de Epidemiologia da Fundação Nacional de Saúde (CENEPI/FUNASA), representa a revista que se dedicou à publicação de caráter técnico-científico orientada para a difusão do conhecimento epidemiológico e voltada para os profissionais dos serviços de saúde.

Em relação ao período selecionado (19922002), refere-se a um momento histórico em que o tema ambiente claramente entrou na agenda política e científica global. O ano de 1992, quando foi realizada a Conferência Rio 92, representa a culminância do tema ambiente, criando as bases para uma nova visão mundial sobre o tema e o início de uma nova era, com a implementação de uma estratégia para o desenvolvimento sustentável usando-se um plano detalhado para o meio ambiente e desenvolvimento no século XXI, a Agenda 212 2. O ano de 2002, quando foi realizada a Rio + 10, na cidade de Joanesburgo, África do Sul, com a constatação dos poucos avanços ou mesmo retrocessos dos compromissos estabelecidos na Agenda 21, marcou o encerramento do ciclo de euforia iniciado em 1992 10. Neste período, no Brasil, ocorreu uma série de eventos interna- cionais e nacionais sobre o tema e teve início, no final dos anos 90, a institucionalização do tema ambiente no setor saúde, tanto em grandes instituições de pesquisa e ensino 11 , como no Ministério da Saúde, por meio da criação da Vigilância Ambiental em Saúde, que se estendeu também para algumas Secretarias Estaduais de Saúde 12

No que se refere aos tipos de textos publicados nas revistas, procurou-se trabalhar com a maior diversidade possível, desde que tivessem em comum o fato de serem submetidos a exames prévios de pareceristas/relatores externos que avaliam o mérito científico dos mesmos. Assim, tendo como referências as normas para publicações das próprias revistas selecionadas, foram incluídos os seguintes tipos de textos: (1) artigos - revisão crítica, atualização, resultados de pesquisas de natureza empírica e experimental ou conceitual, análises e avaliações de tendências teórico-metodológicas da saúde coletiva; (2) opinião - opinião qualificada sobre tópico específico; (3) debate - artigo teórico acompanhado de cartas críticas assinadas por autores de diferentes instituições, seguidas de resposta do autor do artigo principal; e (4) notas - relatos de resultados parciais ou preliminares de estudos originais ou avaliativos, contendo dados e informações inéditas e relevantes para a saúde pública. Foram excluídos os textos que não passam pela avaliação prévia de pareceristas/relatores externos, os quais são: cartas ao editor, editoriais e relatórios de reuniões ou oficinas de trabalho, e reprodução de artigos publicados em outros periódicos (estes dois últimos tipos restritos ao Inf Epidemiol SUS).

Em relação à seleção dos artigos, considerou-se extremamente difícil estabelecer a priori um critério que defina os textos que devem ser incluídos ou excluídos. Isto decorre da própria dificuldade de se definir uma fronteira bem demarcada do que é e do que não é uma pesquisa e produção científica na saúde coletiva que possa ser considerada como tratando especificamente do tema ambiente, já que os seres humanos nascem, crescem, vivem, se deslocam e realizam todas as suas atividades (do trabalho ao lazer) em "ambientes". Assim, o critério de seleção adotado foi incluir todos os textos em que os autores claramente procuraram identificar o texto com o tema, utilizando os seguintes termos por busca: ambiente ou ambiental, de forma simples ou conjugada, no título (indicando o pertencimento do texto ao tema) ou nas palavras-chave (indicando a proximidade ou o pertencimento do texto ao tema). Procurou-se definir um critério bastante 
amplo, de modo a contribuir para o entendimento dos temas que vêm sendo incluídos como relacionados ao "ambiente", o que incluí aqueles identificados com as questões "ambientais" na área da saúde coletiva.

Para cada texto selecionado foi preenchida uma ficha contendo dez itens para análise: (1) autores e instituições; (2) palavras-chave; (3) problema abordado; (4) noção de saúde; (5) noção de ambiente; (6) abordagem teóricometodológica utilizada; (7) escala espacial de análise e localização geográfica do estudo; (8) grupos populacionais incluídos no estudo; (9) participação dos diferentes atores sociais ou grupos populacionais específicos (moradores expostos, comunidades, trabalhadores etc.), envolvidos no problema na construção do conhecimento; e (10) encaminhamento de propostas para a solução do problema.

\section{Resultados}

\section{Total de artigos e tipos de textos}

Foram identificados 115 textos no período, sendo metade publicada em Cad Saúde Pública $13,14,15,16,17,18,19,20,21,22,23,24,25,26,27,28,29,30,31,32,33$, $34,35,36,37,38,39,40,41,42,43,44,45,46,47,48,49,50,51,52,53,54$, $55,56,57,58,59,60,61,62,63,64,65,66,67,68,69,70,36,0 \%$ na Rev Saúde Pública 71,72,73,74,75,76,77,78,79,80,81,82, $83,84,85,86,87,88,89,90,91,92,93,94,95,96,97,98,99,100,101,102$, 103,104,105,106,107,108,109,110,111 e 7,0\% em cada uma das duas outras, Ciênc Saúde Coletiva 112,113,114, 115,116,117,118,119 e Inf Epidemiol SUS 120,121,122, $123,124,125,126,127$. Em relação ao número de textos publicados por ano, não houve uma regularidade ou mesmo tendência gradual de aumento ao longo dos anos. Os anos de 1998 e 2002 apresentaram o maior número de textos publicados (17 em cada um destes anos). Este número cai drasticamente para 4 em 2000, quando o tema ambiente já estava consolidado na saúde coletiva. Para se ter uma idéia do total de textos selecionados em relação ao universo de textos publicados nas revistas, tomamos como referência o total de artigos publicados na revista Cad Saúde Pública no período de 1994 a 2002, para a qual existe estatística disponível na base de dados SciELO. Neste período, foram publicados 1.002 textos no Cad Saúde Pública, sendo que no levantamento realizado para este trabalho foram selecionados 47 nesta mesma revista, o que corresponde a $4,69 \%$ do total de textos publicados. Em relação aos tipos de textos publicados, 99 (86,0\%) eram artigos científicos. Opiniões qualificadas sobre temas corresponderam a $8,0 \%$ e notas de pesquisas a $4,0 \%$.
Somente dois textos foram publicados para debates.

Breve levantamento realizado na base de dados MEDLINE para o mesmo período, tendo como referência de busca os termos environment e environmental no título (title words) e nos descritores (subject descriptor), e Brazil como palavra-chave geral (words), encontramos 198 textos, dos quais $71(36,0 \%)$ foram em revistas publicadas no país, sendo que destes, 32 fazem parte do universo de 115 textos selecionados para este artigo. As outras revistas nacionais, além do Cad Saúde Pública e Rev Saúde Pública, que apareceram nesta busca no MEDLINE foram: Anais da Academia Brasileira de Ciências (An Acad Bras Ciênc), 2 textos; Brazilian Journal of Biology (Braz J Biol), 14 textos; Brazilian Journal of Medical and Biological Research (Braz J Med Biol Res), 1 texto; Jornal de Pediatria (J Pediatr), 2 textos; Memórias do Instituto Oswaldo Cruz (Mem Inst Oswaldo Cruz), 8 textos; Revista da Escola de Enfermagem da USP (Rev Esc Enfermagem USP), 1 texto; Revista do Instituto de Medicina Tropical de São Paulo (Rev Inst Med Trop São Paulo), 1 texto; Revista da Sociedade Brasileira de Medicina Tropical (Rev Soc Bras Med Trop), 2 textos; e São Paulo Medical Journal (São Paulo Med J), 1 texto.

\section{Instituições e autores}

No que se refere às instituições presentes nos textos, foram identificadas 107 que apareceram pelo menos uma vez, sendo 83 nacionais $(77,6 \%)$ e 24 internacionais (22,4\%). Das 24 instituições internacionais, metade se encontrava na América Latina, sendo 5 do México, 3 do Chile, 2 da Argentina e 2 da Colômbia. Na Europa foram identificadas $25,0 \%$ das instituições internacionais e $12,5 \%$ na América do Norte (excluindo o México, situado na América Latina). Só duas instituições foram identificadas como pertencentes ao continente africano.

As instituições nacionais (Tabela 1) estiveram distribuídas em 15 Unidades da Federação pertencentes a cinco regiões do país. A Região Sudeste concentrou $57,8 \%$ das instituições identificadas, sendo que quase $50,0 \%$ somente no eixo Rio de Janeiro-São Paulo. Em seguida vêm as regiões Sul (16,9\%), Nordeste (14,5\%) e Centro-oeste $(8,4 \%)$. Na Região Norte foram identificadas somente duas instituições $(2,4 \%)$, situadas nos Estados do Pará e Amazonas.

Em relação ao tipo de instituições identificadas, das 83 nacionais, 59 (71,0\%) eram instituições de C\&T (pesquisa, ensino e desenvolvimento tecnológico), 17 (21,0\%) associadas aos serviços, 5 (6,0\%) Organizações Não-governamen- 
Número de instituições e total de citações das instituições nacionais por grandes regiões e Unidades da Federação.

\begin{tabular}{|c|c|c|c|c|}
\hline $\begin{array}{l}\text { Grandes regiões } \\
\text { e Unidades da Federação }\end{array}$ & $\begin{array}{l}\text { Número de } \\
\text { instituições }\end{array}$ & $\begin{array}{l}\text { Percentual de } \\
\text { instituições }\end{array}$ & $\begin{array}{l}\text { Número de } \\
\text { citações das } \\
\text { instituições }\end{array}$ & $\begin{array}{c}\text { Percentual de } \\
\text { citações das } \\
\text { instituições }\end{array}$ \\
\hline Brasil & 83 & 100,0 & 172 & 100,0 \\
\hline Região Norte & 2 & 2,4 & 3 & 1,7 \\
\hline Amazonas & 1 & & 1 & \\
\hline Pará & 1 & & 2 & \\
\hline Região Nordeste & 12 & 14,5 & 13 & 7,6 \\
\hline Ceará & 4 & & 4 & \\
\hline Pernambuco & 4 & & 5 & \\
\hline Sergipe & 2 & & 2 & \\
\hline Bahia & 2 & & 2 & \\
\hline Região Sudeste & 48 & 57,8 & 131 & 76,2 \\
\hline Minas Gerais & 7 & & 9 & \\
\hline Rio de Janeiro & 18 & & 59 & \\
\hline São Paulo & 23 & & 63 & \\
\hline Região Sul & 14 & 16,9 & 16 & 9,3 \\
\hline Paraná & 4 & & 4 & \\
\hline Santa Catarina & 2 & & 3 & \\
\hline Rio Grande do Sul & 8 & & 9 & \\
\hline Região Centro-oeste & 7 & 8,4 & 9 & 5,2 \\
\hline Mato Grosso do Sul & 1 & & 1 & \\
\hline Mato Grosso & 2 & & 2 & \\
\hline Distrito Federal & 4 & & 6 & \\
\hline
\end{tabular}

tais (ONGs) e $1(1,2 \%)$ empresa privada. Somente uma instituição não foi possível classificar em relação aos tipos anteriormente citados. Entre as instituições internacionais, o percentual de instituições de C\&T sobe para 79,0\% e relacionadas aos serviços cai para $8,0 \%$. Nenhuma ONG foi identificada, surgindo, entretanto, $2(8,0 \%)$ instituições intergovernamentais (Organização Mundial da Saúde - OMS e Organização Pan-Americana da Saúde - OPAS).

Como uma mesma instituição pode aparecer em mais de um artigo, foi levantado também o total de citações das instituições nos 115 textos selecionados. Para cada artigo considerou-se apenas uma citação de cada instituição, de modo que um artigo com três autores de uma mesma instituição correspondeu a apenas uma citação. Entretanto, é importante observar que houve casos, ainda que muito poucos, em que um único autor apresentava dois vínculos institucionais, considerando-se neste caso duas instituições. A importância deste tipo de levantamento é poder identificar, de modo quantitativo, o envolvimento das instituições na produção científica.

Foram identificadas 198 citações de instituições, correspondendo a uma média de 1,7 instituições por texto. Em relação as $26(13,1 \%)$ citações de instituições internacionais, os porcentuais de citações permaneceram os mesmos em relação às instituições identificadas. Em relação as $172(86,9 \%)$ citações de instituições nacionais, pode-se verificar na Tabela 1 que a Região Sudeste concentrou a maioria (76,2\%), sendo que só o eixo Rio de Janeiro-São Paulo correspondeu a $70,9 \%$ do total de citações. Comparando-se na Tabela 1 o percentual do número de instituições com o do número de citações, verifica-se que somente para a Região Sudeste houve crescimento, com decréscimo em todas as outras regiões.

Em relação ao tipo de instituições nacionais que apareceram citadas, $83,7 \%$ eram instituições de C\&T (único tipo de instituição que apresentou crescimento quando comparado o porcentual de instituições citadas com o de insti- 
tuições identificadas), 12,2\% associadas aos serviços e 2,9\% a ONGs. Em relação às citações das instituições internacionais, 83,3\% eram de C\&T, 12,5\% instituições associadas aos serviços e 8,3\% instituições intergovernamentais.

Em relação às instituições nacionais, a concentração da presença de instituições de C\&T da Região Sudeste, principalmente situadas no eixo Rio de Janeiro-São Paulo, fica bastante evidente quando levantamos as que foram citadas pelo menos cinco vezes, sendo estas: (1) Escola Nacional de Saúde Pública, Fundação Oswaldo Cruz (ENSP/FIOCRUZ) ( $\mathrm{n}=28$ citações); (2) Faculdade de Saúde Pública, Universidade de São Paulo (FSP/USP) ( $n=21$ citações); (3) Faculdade de Medicina, Universidade de São Paulo (FM/USP) ( $\mathrm{n}=13$ citações); (4) Instituto Oswaldo Cruz, Fundação Oswaldo Cruz (IOC/FIOCRUZ) ( $\mathrm{n}=7$ citações); (5) Centro de Informação em Ciência e Tecnologia, Fundação Oswaldo Cruz (CICT/FIOCRUZ) ( $n=5$ citações); e (6) Núcleo de Estudos em Saúde Coletiva, Universidade Federal do Rio de Janeiro (NESC/UFRJ) ( $n=5$ citações). Estas seis instituições (7,2\% do total de $83)$, todas de C\&T, apareceram citadas 79 vezes, o que correspondeu a $46,0 \%$ do total de citações das instituiçõos nacionais.

Em relação ao número de instituições envolvidas em cada artigo (Tabela 2 ), 40,8\% envolveram apenas uma instituição e exatos $40,0 \%$ duas instituições, o que aponta para um quadro em que pouco mais de $80,0 \%$ dos artigos envolveram no máximo duas instituições. Em relação à cooperação entre as instituições nacionais, particularmente entre pelo menos uma instituição de C\&T e uma instituição associada aos serviços, foram encontrados apenas 16 $(13,9 \%)$. Outros três textos envolveram instituições associadas aos serviços com instituições intergovernamentais, ONGs e instituições de C\&T. Em relação à cooperação entre instituições de C\&T nacionais e internacionais, encontramos apenas quatro $(3,5 \%)$ textos.

Em relação aos autores (Tabela 3), 16,5\% dos textos envolveram apenas um autor e o maior percentual foi de artigos envolvendo dois autores $(27,8 \%)$. Totalizando os artigos que tiveram até dois autores temos um porcentual de $44,3 \%$. Os artigos que tiveram cinco ou mais autores totalizaram 18,3\%. Quando analisamos o número de artigos publicados por um mesmo autor responsável pela primeira autoria, verificamos uma grande concentração, conforme pode ser visto na Tabela 4 . Um primeiro autor respondeu por mais de $11,3 \%$ do total de textos. Os primeiros autores que publicaram três ou mais textos $(n=4)$ totalizaram $4,4 \%$ dos autores e responderam por $21,7 \%$ dos textos. Estes quatro autores possuem vínculo com quatro das instituições citadas pelo menos cinco vezes (FSP/USP; CICT/FIOCRUZ; ENSP/ FIOCRUZ; NESC/UFRJ) e atuam diretamente em programas de pós-graduação em saúde coletiva.

\section{Palavras-chave}

Em relação às palavras-chave foram encontradas 295 diferentes, simples ou compostas, que totalizaram 480 citações. Estas palavras-chave foram agrupadas em 23 grupos diferentes que podem ser identificados na Tabela 5 . As palavras-chave associadas às doenças e agravos compuseram o maior grupo, com quarenta identificadas, tais como exemplo: cólera, doença de Chagas, esquistossomose e câncer. Embora as palavras-chaves associadas a métodos de avaliação e análise tenham estado em segundo lugar em relação ao total de identificadas, ocupam o primeiro lugar em termos de palavraschave mais citadas nos textos, sendo exemplos: ecologia de vetores; exposição ambiental e ocupacional; epidemiologia; monitoramento ambiental.

Das palavras-chave que tiveram pelo menos cinco citações, apenas $16(5,4 \%)$ foram responsáveis por 117 (25,0\%) citações (Tabela 6). Entre essas palavras-chave aparecem aquelas associadas aos métodos de avaliação e análise (ecologia de vetores, epidemiologia, estudos de caso e controle), monitoramento da alteração do estado ambiental e da exposição (exposição ambiental e ocupacional, monitoramento ambiental), contaminação, degradação e poluição (poluição ambiental e impactos ambientais), lugar (ambiente e meio ambiente), saúde (saúde ambiental e ocupacional, saúde pública e saúde do trabalhador), vetores (Anopheles) e agentes químicos (mercúrio).

\section{Problemas abordados}

Em relação aos problemas ambientais que se tornaram objetos de investigação procuramos reuni-los por grupos, tendo por base os problemas definidos na Agenda 21 e na publicação Nosso Planeta, Nossa Saúde, da OPAS/OMS para a Rio 92 128, identificando 14 (Tabela 7). O grupo de problemas que concentrou o maior número de artigos foi poluição, contaminação $e$ intoxicação por produtos químicos no meio ambiente e seu potencial de impactos sobre a saúde, com 32 (28,0\%), sendo seguido pelo grupo presença de vetores, hospedeiros e reservatórios no meio ambiente e seu potencial de impactos sobre a saúde, com $22(19,0 \%) \mathrm{e}$, em terceiro, o 
grupo questões teóricas e metodológicas para a investigação e monitoramento dos problemas ambientais, com 19 (16,5\%). Estes três grupos foram responsáveis por 73 dos 115 artigos (63,5\%).

Conforme podemos observar na Figura 1, verifica-se ao longo do período uma queda na publicação dos textos pertencentes ao grupo relacionado à presença de vetores, hospedeiros $e$ reservatórios, que foram expressivos até $1996 \mathrm{e}$ intermitentes a partir daí, e um aumento dos textos pertencentes ao grupo relacionado à poluição, contaminação e intoxicações químicas a partir de 1997. Interessante observar que foram encontrados poucos textos relacionados ao grupo de controle e prevenção de vetores, hospedeiros e reservatórios, sendo irregularmente distribuídos ao longo do período. De qualquer modo, deve-se observar que para este grupo existem outros periódicos científicos, tais como a Rev Soc Bras Med Trop, a Rev Inst Med Trop São Paulo e Mem Inst Oswaldo Cruz, que aparecem em outros estudos sobre a produção científica no campo da saúde coletiva 5,9 , onde textos mais voltados para o controle e a prevenção podem ter sido publicados. Em relação aos textos relacionados ao grupo de controle e prevenção da poluição, contaminação e intoxicações químicas, encontramos apenas um em 2002.

Quando relacionamos os textos dos grupos de diagnósticos (presença de vetores, hospedeiros e reservatórios e poluição, contaminação e intoxicações químicas) com os dos grupos de controle e prevenção destes problemas encontramos o seguinte quadro: relacionados aos vetores, hospedeiros e reservatórios encontramos 27 textos, dos quais apenas 5 pertencentes ao grupo voltado para o controle e prevenção (média de um texto deste grupo para 4,4 do grupo relacionado ao diagnóstico); relacionados à poluição, contaminação e intoxicações químicas encontramos 33 textos, dos quais somente 1 pertencente ao grupo voltado para o controle e a prevenção destes problemas (média de 1 texto deste grupo para 32 do grupo relacionado ao diagnóstico).

\section{Noções de saúde e ambiente}

Conforme pode-se verificar na Figura 2, em relação às noções de saúde encontrou-se que predominaram as baseadas no modelo biológico do processo saúde-doença, o que inclui em sua grande maioria as abordagens centradas na $a v a-$ liação da exposição (ecologia de vetores, avaliações ambientais e avaliações toxicológicas humanas e ambientais), na epidemiologia e parte das abordagens centradas na análise espacial. As noções de saúde baseadas na busca da
Tabela 2

Número de instituições envolvidas em cada um dos artigos selecionados.

\begin{tabular}{lcc}
\hline Número de instituições & Total de artigos & $\begin{array}{c}\text { Percentual em } \\
\text { relação ao total } \\
\text { de artigos }\end{array}$ \\
\hline 1 & 47 & 40,8 \\
2 & 46 & 40,0 \\
3 & 17 & 14,8 \\
4 & 4 & 3,5 \\
5 & 1 & 0,9 \\
Total & 115 & 100,0 \\
\hline
\end{tabular}

Tabela 3

Número de autores envolvidos em cada um dos artigos selecionados.

\begin{tabular}{lcc}
\hline Número de autores & Total de artigos & $\begin{array}{c}\text { Percentual em } \\
\text { relação ao total } \\
\text { de autores }\end{array}$ \\
\hline 1 & 19 & 16,5 \\
2 & 32 & 27,8 \\
3 & 20 & 17,5 \\
4 & 23 & 20,0 \\
5 & 9 & 7,8 \\
6 & 4 & 3,5 \\
7 & 3 & 2,6 \\
8 & 1 & 0,9 \\
9 & 3 & 2,6 \\
11 & 1 & 0,9 \\
Total & 115 & 100,0 \\
\hline
\end{tabular}

Tabela 4

Número de artigos por primeiro autor.

\begin{tabular}{lccc}
\hline $\begin{array}{l}\text { Número } \\
\text { de artigos }\end{array}$ & $\begin{array}{c}\text { Percentual em } \\
\text { relação ao total } \\
\text { de artigos }\end{array}$ & $\begin{array}{c}\text { Número de } \\
\text { primeiro autor } \\
\text { responsável }\end{array}$ & $\begin{array}{c}\text { Percentual em } \\
\text { relação ao total } \\
\text { de autores }\end{array}$ \\
\hline 13 & 11,3 & 1 & 1,1 \\
5 & 4,3 & 1 & 1,1 \\
4 & 3,5 & 1 & 1,1 \\
3 & 2,6 & 1 & 1,1 \\
10 & 8,7 & 5 & 5,6 \\
80 & 69,6 & 80 & 90,0 \\
115 & 100,0 & 89 & 100,0 \\
\hline
\end{tabular}


Grupos de palavras-chave em ordem decrescente por grupos.

\begin{tabular}{|c|c|c|}
\hline Grupo de palavras-chave & $\begin{array}{l}\text { Número de } \\
\text { palavras-chave } \\
\text { pertencentes } \\
\text { ao grupo }\end{array}$ & $\begin{array}{l}\text { Número de } \\
\text { citações das } \\
\text { palavras-chave } \\
\text { pertencentes } \\
\text { ao grupo }\end{array}$ \\
\hline Doenças e agravos & 40 & 50 \\
\hline Métodos de avaliação e análise & 34 & 72 \\
\hline Busca de soluções, controle, cuidado e prevenção & 28 & 37 \\
\hline Processos geradores de degradação, contaminação e doenças & 20 & 21 \\
\hline Monitoramento da alteração do estado ambiental e da exposição & 20 & 43 \\
\hline Vetores & 16 & 38 \\
\hline Agentes químicos & 15 & 25 \\
\hline Lugar & 15 & 25 \\
\hline Contaminação, degradação e poluição & 12 & 27 \\
\hline Saúde & 11 & 38 \\
\hline Condição & 10 & 11 \\
\hline Águas, resíduos e saneamento & 9 & 13 \\
\hline Produtos e resíduos & 8 & 11 \\
\hline Grupos populacionais & 8 & 9 \\
\hline Risco ou fatores de risco & 7 & 10 \\
\hline Vigilância & 6 & 7 \\
\hline Agentes biológicos & 6 & 7 \\
\hline Hospedeiros e reservatórios & 5 & 5 \\
\hline Eventos & 4 & 4 \\
\hline Ciência para o desenvolvimento sustentável & 4 & 6 \\
\hline Agentes físicos & 3 & 3 \\
\hline Participação & 2 & 2 \\
\hline Outras & 13 & 16 \\
\hline Total de grupos: 23 & 296 & 480 \\
\hline
\end{tabular}

compreensão dos aspectos histórico-sociais no processo saúde-doença constituíram cerca de 1/4 do total e incluíram, além de todos os textos que tiveram a abordagem centrada no processo histórico-social, cerca de metade dos textos que tiveram a abordagem centrada na análise espacial.

Em relação às noções de ambiente, observa-se um perfil semelhante às noções de saúde, tendo predominado as centradas nos aspectos biofísicos. A pequena diferença que aparece é explicada pelo fato de, embora alguns textos adotarem uma noção de saúde predominantemente biológica, quando procuraram tratar dos aspectos do ambiente ou ambientais que contribuíram para o processo saúde-doença, trabalharam com uma noção de ambiente centrada nos aspectos histórico-sociais. Por exemplo, três textos que tiveram uma abordagem centrada na avaliação da exposição de populações a agentes patogênicos (biológicos ou químicos), quando trataram dos aspectos am- bientais o fizeram tendo por base um enfoque predominantemente (não somente) centrado nos aspectos histórico-sociais. Em dois textos que tiveram a abordagem centrada na epidemiologia encontramos a mesma situação.

\section{Abordagens teórico-metodológicas}

Em relação às abordagens adotadas, em 55 textos $(47,8 \%)$ predominou a centrada na avaliação da exposição (identificação e quantificação da presença de vetores, agentes biológicos e químicos que, em casos de contato humano, podem ocasionar doenças). Neste universo da avaliação da exposição, abordagens que procuraram identificar e quantificar a presença de agentes químicos (avaliação toxicológica humana e ambiental) e biológicos (avaliação ambiental) estiveram presentes em mais da metade dos textos. Ainda neste universo, abordagens influenciadas pelo modelo ecológico (agentehospedeiro-ambiente) 129 vêm em seguida, com 
quase metade, predominando entre estas os estudos que tiveram por base a ecologia de vetores. Abordagens mais recentes, centradas na construção de indicadores ambientais e de saúde, e em enfoques ecossistêmicos totalizaram um texto para cada uma.

A epidemiologia constituiu o segundo maior grupo de abordagens, totalizando $27(23,5 \%)$ textos, sendo dominantes os estudos em que foram aplicados inquéritos em um grupo populacional definido em função do problema, os desenhos tipo caso-controle e os estudos descritivos utilizando bases de dados disponíveis, principalmente sobre doenças como o câncer.

Abordagens centradas no processo histórico e social (análises sobre os perfis diferenciados de saúde-doença e sua estreita relação com o contexto histórico, o modelo de desenvolvimento e as condições de vida e trabalho dos diferentes grupos sociais), totalizaram $15,6 \%$ dos textos, sendo que cerca de $1 / 4$ teve como problema a questão da educação e o outro 1/4 tratou de problemas relacionados às condições de vida e trabalho. A outra metade dos textos des-
Tabela 6

Lista das palavras-chave que tiveram pelo menos cinco citações.

\begin{tabular}{lcc}
\hline Palavras-chave & $\begin{array}{c}\text { Número de } \\
\text { citações }\end{array}$ & $\begin{array}{c}\text { Percentual } \\
\text { de citações }\end{array}$ \\
\hline Ecologia de vetores & 16 & 13,7 \\
Saúde ambiental & 12 & 10,3 \\
Exposição ambiental & 11 & 9,4 \\
Exposição ocupacional & 8 & 6,9 \\
Poluição ambiental & 8 & 6,9 \\
Saúde ocupacional & 7 & 6,0 \\
Ambiente & 6 & 5,1 \\
Epidemiologia & 6 & 5,1 \\
Mercúrio & 6 & 5,1 \\
Monitoramento ambiental & 6 & 5,1 \\
Saúde pública & 6 & 5,1 \\
Estudos de caso e controle & 5 & 4,3 \\
Anopheles & 5 & 4,3 \\
Impactos ambientais & 5 & 4,3 \\
Meio ambiente & 5 & 4,3 \\
Saúde do trabalhador & 5 & 4,3 \\
Total de palavras: 16 & 117 & 100,0 \\
& & \\
& 5 & 5,3 \\
& 5 & 5
\end{tabular}

Grupos de problemas ambientais e de saúde identificados nos artigos.

\begin{tabular}{|c|c|c|}
\hline Grupos de problemas & $\begin{array}{l}\text { Número } \\
\text { de artigos } \\
\text { identificados }\end{array}$ & $\begin{array}{l}\text { Percentual } \\
\text { de artigos } \\
\text { identificados }\end{array}$ \\
\hline $\begin{array}{l}\text { Poluição, contaminação e intoxicação por produtos químicos } \\
\text { no meio ambiente e seu potencial de impactos sobre a saúde }\end{array}$ & 32 & 27,8 \\
\hline $\begin{array}{l}\text { Presença de vetores, hospedeiros e reservatórios no meio } \\
\text { ambiente e seu potencial de impactos sobre a saúde }\end{array}$ & 22 & 19,1 \\
\hline $\begin{array}{l}\text { Questões teóricas e metodológicas para a investigação } \\
\text { e monitoramento dos problemas ambientais }\end{array}$ & 19 & 16,5 \\
\hline Doenças transmitidas e baseadas nas águas & 9 & 7,8 \\
\hline $\begin{array}{l}\text { Modelo de desenvolvimento - aspectos demográficos, pobreza, } \\
\text { utilização de recursos (renováveis e não-renováveis) } \\
\text { e políticas macroeconômicas }\end{array}$ & 6 & 5,2 \\
\hline $\begin{array}{l}\text { Controle e prevenção da presença de vetores, hospedeiros e reservatórios } \\
\text { no meio ambiente e seu potencial de impactos sobre a saúde }\end{array}$ & 5 & 4,3 \\
\hline Modelo de educação & 5 & 4,3 \\
\hline $\begin{array}{l}\text { Serviços de saúde e seus impactos ambientais e à saúde, e os impactos } \\
\text { ambientais nos serviços de saúde }\end{array}$ & 5 & 4,3 \\
\hline Condições de trabalho & 4 & 3,5 \\
\hline Desigualdades sócio-ambientais & 4 & 3,5 \\
\hline Energia & 1 & 0,9 \\
\hline Alimentos & 1 & 0,9 \\
\hline Políticas públicas & 1 & 0,9 \\
\hline $\begin{array}{l}\text { Controle e prevenção da poluição, contaminação e intoxicação } \\
\text { por produtos químicos no meio ambiente e seu potencial de impactos } \\
\text { sobre a saúde }\end{array}$ & 1 & 0,9 \\
\hline Total de grupos: 14 & 115 & 100,0 \\
\hline
\end{tabular}




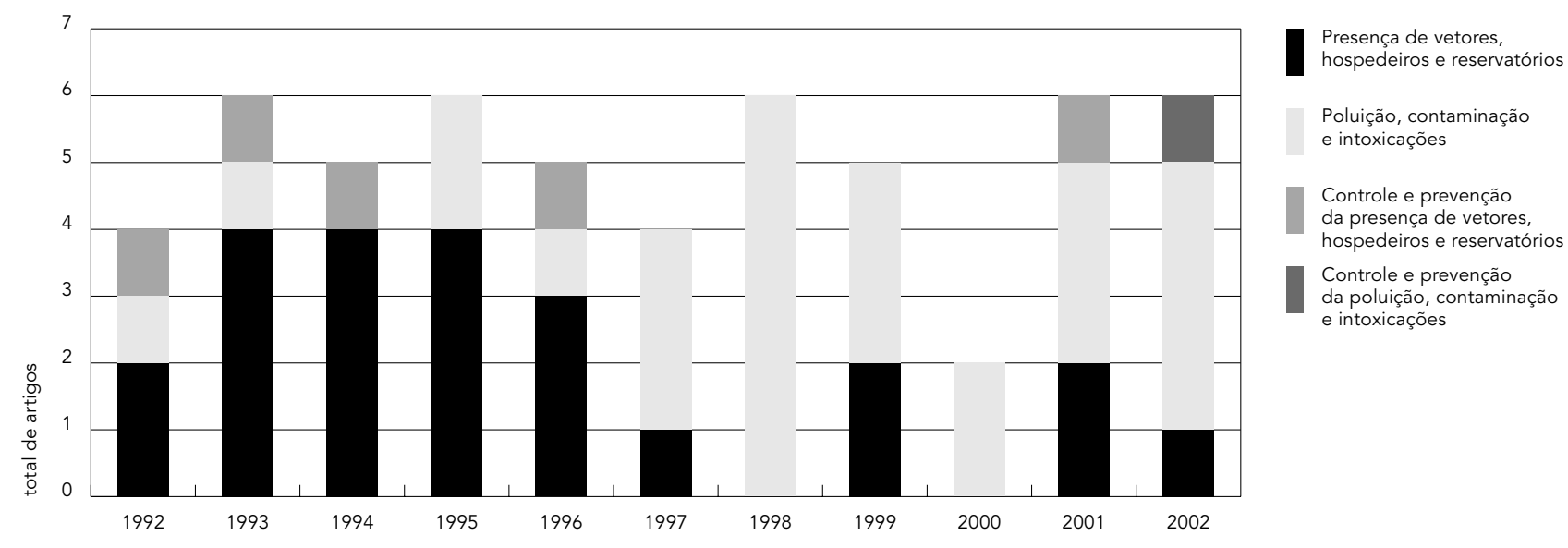

te universo foi bastante diversificada, sendo que somente dois trataram do processo histórico sobre o tema ambiente no setor saúde no Brasil.

Os textos que tiveram como abordagem dominante a análise espacial estiveram em torno de $10,0 \%$ do total, sendo que destes, cerca de $1 / 4$ tratou da questão das desigualdades sociais. Os outros 3/4 trataram de uma diversidade de temas, como filariose linfática, malária, leptospirose, abastecimento de água, poluição atmosférica e trabalhadores expostos ao mercúrio, por exemplo.

\section{Escala espacial de análise}

Em relação à escala espacial, fora do país, os textos abordam desde regiões de um continente, como a África Ocidental, até os países em desenvolvimento ou de economia periférica, passando por povoados e cidades em países da América Latina, como Argentina e Colômbia.

Em relação ao Brasil, citado como unidade de análise, encontramos nove textos. Destes, dois trataram do histórico da introdução do tema ambiente no campo da saúde no país e somente um tratou da análise da situação de saúde, tendo como referência as mudanças ambientais. Os outros seis trataram de temas diversos, como saúde do trabalhador, saúde da criança, doença de Chagas, educação em saúde, segurança química e inter-relações entre saneamento, saúde e ambiente.
Diminuindo a escala espacial para regiões do país, encontramos apenas dois artigos. Um sobre o Norte do Brasil (comunidades indígenas afetadas pelos projetos de eletrificação) 55 e outro sobre a Região Amazônica (impactos dos processos de migração e colonização) 21 .

Tendo como nível de análise o Estado, três foram citados, sendo estes: Pernambuco ( $V i$ brio cholerae $\mathrm{O}_{1}$ em amostras de ambientes aquáticos e de alimentos) 41; Sergipe (incidência e distribuição espacial da leishmaniose visceral) 124; e Ceará (programa de capacitação em saúde e ambiente) 119.

Em relação aos municípios, procuramos identificar todos os que foram citados nos estudos, tendo sido encontrados 54 diferentes, distribuídos por 13 Unidades da Federação. Importante observar que para a grande maioria dos estudos realizados, a unidade de análise não foi o município, mas sim um lugar específico dentro do município, tal como uma área contaminada ou de lixão, um bairro ou um distrito, uma zona ou região, um edifício ou um hospital. Do total de municípios, 17 se situavam no Estado de São Paulo, 9 no Rio Grande do Sul, 5 no Rio de Janeiro, 5 no Pará, 5 em Minas Gerais, 4 na Bahia, 2 no Paraná, 2 em Pernambuco, 1 no Espírito Santo, 1 em Santa Catarina, 1 no Ceará, 1 em Alagoas e 1 no Maranhão.

Nem todos esses 54 municípios tiveram a mesma atenção como área de estudo. Entre os municípios que foram mencionados mais de 
uma vez como área de estudo, os mais citados foram: Rio de Janeiro ( $n=9)$; São Paulo $(n=8)$; Pariquera Açu, São Paulo ( $n=8)$; Pelotas, Rio Grande do Sul $(n=2)$; Fortaleza, Ceará $(n=2)$; Poconé, Mato Grosso $(n=2)$.

\section{Grupos populacionais incluídos nos estudos}

Mais da metade dos textos se referiu às populações de um modo geral, indo desde a população do planeta, passando por populações de estados e municípios e chegando até as populações no nível local, como moradores de um bairro ou vivendo próximo a uma fonte de poluição, expostas a problemas específicos. Entre grupos específicos, os que mereceram maior número de estudos específicos foram os trabalhadores (12 textos identificados), envolvendo desde trabalhadores rurais, trabalhadores industriais e trabalhadores em serviços bancários e de saneamento ou vítimas de acidentes de trabalho notificados. Crianças constituíram o grupo alvo em nove estudos, sendo que em dois textos constituíram subgrupos de estudo. Índios como grupo alvo de estudo apareceram em somente um texto. Para 31 (27,0\%) textos, a identificação da população geral ou grupos populacionais específicos não se aplicava.

\section{Participação dos atores envolvidos nos problemas}

Em relação à participação dos diferentes atores sociais ou grupos populacionais específicos (moradores expostos, comunidades, trabalhadores etc.), a grande maioria dos textos $(78,3 \%)$ não se referiu a nenhuma forma de participação. Somente $21,7 \%(n=25)$ previam a participação como importante fator.

No universo dos textos que previam participação, seis procuraram valorizar e incorporar o conhecimento dos mesmos como elementos para ampliar a consciência sobre as inter-relações entre as questões ambientais e de saúde. Dentre estes, cinco eram direcionados à educação em saúde e meio ambiente, e um tratava dos métodos de mapeamento ambiental como instrumento didático e de debate com a população leiga sobre suas condições de vida e inserção no espaço urbano. Outros nove previam a participação como instrumento metodológico para melhor definição dos problemas e das variáveis, com quatro destacando a importância da participação dos expostos (trabalhadores e comunidades) aos riscos ambientais e cinco apontando para a participação de grupos populacionais organizados, ONGs, poder público local e população local na definição das
Figura 2

Noções de saúde e ambiente predominantemente centradas nos aspectos biológicos ou biofísicos e predominantemente centradas no processo histórico e social.

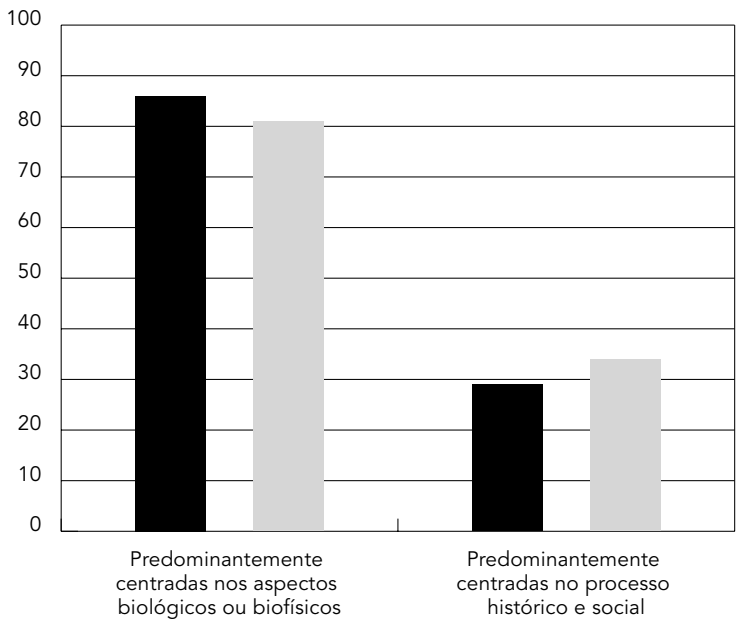

Noção de saúde Noção de ambiente

unidades e variáveis de análises. Os outros dez textos previam a participação como elemento central para a gestão e tomadas de decisões sobre as questões ambientais e de saúde. Dentre estes, dois eram orientados em direção ao SUS, prevendo tanto uma maior participação nos Conselhos Municipais de Saúde que incorporasse as questões ambientais, como um maior controle social na reorganização do próprio sistema nacional de saúde. Outros dois trataram da participação dos trabalhadores na gestão e tomadas de decisões sobre os problemas ambientais e de saúde nos locais de trabalho. Outros dois previam uma ampla participação voltada para a gestão e tomada de decisões setoriais, no caso geração de energia e produção, armazenamento, distribuição, transporte e descarte de produtos químicos. Outros dois centravam-se na participação voltada para a definição ou redefinição dos processos econômicos e padrões de produção e consumo. Os dois últimos tratavam da participação de um modo bastante geral, mas acentuando sua importância na gestão e tomadas de decisões.

\section{Encaminhamento de propostas para soluções dos problemas}

Em relação às propostas de soluções dos problemas ambientais e de saúde analisados, cerca de metade $(50,4 \%)$ dos textos não propuse- 
ram ou apontaram algum encaminhamento. Dentre os textos que propuseram algum encaminhamento, identificamos três grupos.

No primeiro grupo, dez textos, identificamos os que apresentaram propostas de soluções mais gerais, de longo e médio prazos. Como propostas de longo prazo, somente dois textos, apontando para a necessidade de mudança do modelo de desenvolvimento e dos padrões de produção e consumo. Os outros envolveram propostas de médio prazo, incluindo: maior participação e controle social; municipalização e universalização do atendimento no SUS; fornecimento de um melhor padrão de vida para a população, atendendo suas necessidades de melhores condições sócio-econômicas (emprego, educação, habitação), sanitárias (acesso à rede de esgoto e água) e ambientais (o que inclui as futuras gerações). Para este grupo, a viabilização destas mudanças exige um esforço dos profissionais de saúde e meio ambiente para a busca de diálogo com os demais atores responsáveis pelo desenvolvimento por meio de práticas interdisciplinares, participativas e intersetoriais, contribuindo para a melhoria das fontes de informações e dos diagnósticos, bem como para processos decisórios mais democráticos para a construção de alternativas para a superação dos atuais problemas ambientais e de saúde.

Com propostas de soluções de problemas específicos, mas que tenham envolvido um enfoque ampliado do problema, indo além das ações pontuais específicas e/ou intersetorial, identificamos um segundo grupo com 27 textos. Ainda que muitos tenham centrado no controle de agentes, fosse com medidas técnicas ou com mudanças na legislação, apontavam para: a criação, ampliação e melhora dos sistemas de informações em uma perspectiva intersetorial; fortalecimento das ações de vigilância em saúde e monitoramento ambiental; ações de educação em saúde ambiental; capacitação de recursos humanos em perspectiva multidisciplinar; investimentos em saúde para a assistência plena em relação ao problema específico; amplo diálogo entre os diferentes atores; desenvolvimento de abordagens integradas para o diagnóstico do problema.

O terceiro grupo, de vinte textos, foi centrado em medidas pontuais, não ampliando as propostas para um conjunto de ações dentro do setor saúde ou mesmo intersetoriais. De modo geral as propostas foram centradas em medidas focadas nos agentes potencialmente causadores de danos, tais como: soluções técnicas (controle químico e biológico de vetores, isolamento de agentes químicos etc.), monitoramen- to ambiental do agente; vigilância em saúde da(s) doença(s); mudança na legislação; medidas de saneamento; educação para mudar comportamentos e atitudes; capacitação de recursos humanos; mais estudos sobre o tema.

\section{Discussão}

Conforme observado na introdução deste artigo, tendo como base o capítulo 35 da Agenda 21 , seis objetivos devem ser atendidos para que ocorra um fortalecimento da base científica para o manejo sustentável, de modo que a ciência possa orientar a gestão prudente do meio ambiente e do desenvolvimento. Procurando atender o objetivo deste trabalho de fornecer subsídios para a conformação de uma ciência orientada para o desenvolvimento sustentável do ambiente e da saúde coletiva, optamos por realizar a discussão tendo como eixo estes seis objetivos, combinando o segundo com o terceiro, e transformando em cinco tópicos de referência para a discussão.

\section{Ampliar e fortalecer as capacidades e potenciais científicos em áreas relevantes}

Conforme se observou no item Total de Artigos e Tipos de Texto, embora o período selecionado (1992-2002) tenha se referido a um momento histórico em que o tema ambiente claramente entrou na agenda política e científica global, constata-se que não houve uma regularidade ou mesmo tendência gradual de aumento do número de textos publicados ao longo dos anos. Este quadro é similar ao encontrado no estudo de Toledo 130 sobre a produção de teses e dissertações defendidas na ENSP no período de 1990 a 1999. Ainda neste item, também se constata que os textos selecionados não ultrapassaram 5,0\% dos textos publicados em uma das revistas (Cad Saúde Pública), coincidindo este percentual com o estudo de Barata \& Goldbaum 5 , no qual constataram que na distribuição das linhas de pesquisa mencionadas pelos bolsistas de produtividade da área, "meio ambiente e desenvolvimento sustentado" aparecia com um percentual inferior a 5,0\%. Assim, os dados deste trabalho, como os de outros estudos, sugerem que a produção científica sobre o tema ambiente não aumentou no período e parece não ultrapassar $5,0 \%$ do total da produção na saúde coletiva.

No item Problemas Abordados, os resultados dos grupos de problemas identificados nos textos (Tabela 7) permitiram verificar que os que tratam da presença de agentes específicos no ambiente (origem química ou biológica) são 
dominantes e juntos totalizaram quase $47,0 \%$. É interessante observar que o período abrangido nesta pesquisa (1992-2002) foi o de consolidação da noção de sustentabilidade associada ao modelo de desenvolvimento, onde estão incluídas as dimensões sociais, políticas e econômicas. Entretanto, os textos que tiveram as políticas públicas e o modelo de desenvolvimento como problema, que no livro Nosso Planeta, Nossa Saúde 128 aparecem como desafios globais para a saúde e o meio ambiente, totalizaram apenas $6,1 \%$ dos textos. O mesmo pode-se considerar sobre o problema das desigualdades sócio-ambientais, pois desde Estocolmo (1972) e principalmente durante o período analisado, aparecem como questão central a ser enfrentada. Entretanto, neste grupo foram encontrados apenas $3,5 \%$ dos textos. Outros problemas ambientais considerados importantes, como água, energia e alimentos 128 , juntos não totalizaram $10,0 \%$, sendo que os dois últimos sequer alcançaram 1,0\% cada.

Parte da explicação para baixa produção de textos sobre problemas prioritários como políticas públicas, modelo de desenvolvimento e desigualdades sócio-ambientais, pode estar relacionada à predominância das noções de saúde e ambiente centradas nos aspectos biológicos e biofísicos simultaneamente, em detrimento das noções centradas nos processos históricos e sociais (item Noções de Saúde e Ambiente). Embora os discursos oficiais de instituições internacionais vinculadas ao setor saúde, como OMS e OPAS, ou ao setor ambiente/ambiental, como o World Resources Institute 131, reconheçam o modelo de desenvolvimento como desafio, acabam reduzindo a saúde à sua dimensão biológica e o ambiente à sua dimensão biofísica. Não por acaso, a definição de saúde ambiental da OPAS/OMS 132 no início dos anos 90 considerava a medicina ambiental e a higiene ambiental como sinônimos e reduzia as mesmas ao estudo dos agentes que se encontravam ou tinham sido introduzidos no ambiente e poderiam produzir doenças e enfermidades. Quando o setor saúde trata do ambiente 128 ou quando o setor ambiente/ambiental trata das inter-relações entre mudanças ambientais e de saúde 131, encontramos uma definição de ambiente que reduz o mesmo às dimensões físicas, químicas e biológicas que envolvem as condições do entorno (ar, águas, solo, alimentos e clima) dos seres humanos, onde podem ser encontrados agentes que direta ou indiretamente causam doenças. Nestas perspectivas, a dimensão social do ambiente é reduzida aos estilos de vida e às escolhas comportamentais ou aos ambientes de trabalho.
Assim, no que se refere à ampliação e fortalecimento das capacidades e potenciais científicos, os resultados demonstram que além de não ter ocorrido um aumento expressivo da produção científica no período na saúde coletiva, sugerem também a não ocorrência de uma mudança qualitativa no modo de definir e tratar os problemas ambientais e de saúde. A produção sobre problemas relevantes, como estudos sobre políticas públicas, modelo de desenvolvimento e desigualdades sócio-ambientais e suas implicações para a sustentabilidade do ambiente e da saúde coletiva não só foi pouco expressiva quantitativamente, mas indica também a predominância de uma produção que qualitativamente pouco associa os problemas de saúde e ambiente às suas dimensões sociais, políticas e econômicas e que, orientada por noções de saúde e ambiente centradas nos aspectos biológicos e biofísicos tende a reduzir os mesmos a estes aspectos.

\section{Produção de conhecimento científico orientado para a formulação de políticas e a tomada de decisões, utilizando a abordagem da precaução}

No item Palavras-chave, verificamos o predomínio de palavras-chaves associadas às doenças e agravos, assim como aos métodos de avaliação e análise. Na Tabela 5, constata-se que a grande maioria das palavras-chaves se encontra em grupos associadas aos agentes ou aos processos geradores de danos à saúde. Palavras-chaves que poderiam estar associadas à formulação de políticas e tomadas de decisões, utilizando a abordagem da precaução só podem ser encontradas em dois grupos (busca de soluções, controle, cuidado e prevenção e ciência para o desenvolvimento sustentável), que juntos totalizaram 32 palavras-chave $(10,8 \%)$ e 43 citações $(8,9 \%)$. Na Tabela 6 , constata-se que entre as palavras-chaves que tiveram pelo menos cinco citações, não aparece nenhuma relacionada aos dois grupos citados anteriormente. Por exemplo, palavras-chave como tomada de decisões, políticas e princípio da precaução foram citadas 1,2 e 1 vez, respectivamente, variando entre um percentual de $0,2 \%$ a $0,4 \%$ de citações.

No item Problemas Abordados, a Tabela 7 nos revela a predominância de problemas relacionados ao diagnóstico (poluição e presença de vetores, totalizando $46,9 \%$ ), enquanto que os estudos voltados para os problemas relacionados às políticas públicas $(0,9 \%)$, à gestão (controle e prevenção, totalizando $5,2 \%$ ) e ao papel dos próprios serviços de saúde $(4,3 \%)$ 
pouco se destacaram. Particularmente no que se refere às políticas públicas e gestão, os dados revelam o quanto terá de se investir em pesquisas e produção científica para temas que são considerados básicos e fundamentais, se quisermos efetivamente fortalecer as capacidades e potenciais científicos na saúde coletiva orientados para a gestão prudente do meio ambiente e do manejo sustentável do desenvolvimento. No que se refere aos serviços de saúde, instâncias fundamentais tanto para o diagnóstico como principalmente para a gestão e o manejo sustentável no nível local, chega a ser surpreendente não se encontrar nenhum texto que trate do seu papel nesta tarefa ou de propostas recentes como a de atenção primária ambiental 133. Ainda no item Problemas Abordados, constatamos, por meio da Figura 1, que são poucos os textos relacionados ao grupo de controle e prevenção, principalmente no que se refere à poluição, contaminação e intoxicações químicas.

Os resultados apresentados nos itens Palavras-chave e Problemas Abordados apontam para uma produção científica predominantemente voltada para o diagnóstico, com o desenvolvimento de políticas públicas e orientação de estratégias de tomadas de decisões para o controle e prevenção, funções básicas da saúde coletiva, ocupando ainda um papel marginal. A pouca produção orientada para a prevenção e o controle se encontra mais presente em temas mais tradicionais como vetores, hospedeiros e reservatórios, sendo ainda deficiente em temas mais recentes como poluição, contaminação e intoxicação por produtos químicos.

O descrito no parágrafo anterior apenas revela uma tendência da produção científica na saúde coletiva sobre o tema ambiente e que aparece de modo mais evidente no item Encaminhamento de Propostas para Soluções dos Problemas, quando se constata que cerca da metade dos textos não propôs ou apontou algum encaminhamento de propostas de soluções dos problemas ambientais e de saúde analisados. E, apesar de encontrarmos propostas que podem e devem ser incluídas na perspectiva de políticas públicas e tomadas de decisões em relação às interfaces entre questões ambientais e de saúde, a grande maioria ainda merece ser bastante trabalhada na perspectiva de tornarem-se formulações bem estruturadas e direcionadas.
Geração de conhecimentos locais, considerando as relações com os planos nacional, regional e internacional

No item Instituições e Autores, constatamos que $57,8 \%$ das instituições nacionais identificadas se concentravam na Região Sudeste, com o Rio de Janeiro e São Paulo concentrando quase $50,0 \%$ de todas as instituições identificadas no país. A Região Norte, no outro extremo, foi a que apresentou a menor concentração de instituições, totalizando $2,4 \%$. Nos extremos, a grande concentração das instituições na Região Sudeste e o mais baixo número e percentual de instituições na Região Norte se repete no Censo 2002 sobre todos os grupos de pesquisas do CNPq (Conselho Nacional de Desenvolvimento Científico e Tecnológico. Distribuição dos grupos de pesquisas segundo a região geográfica, 2002. http://www.cnpq.br, acessado em 20/Mai/2004), nos grupos de pesquisas em epidemiologia identificados no estudo de Guimarães et al. 9, e nos da localização das instituições responsáveis pela publicação de revistas científicas sobre a temática saúde pública ou saúde coletiva identificadas no estudo de Rummler \& Spinola 134, de modo que os porcentuais respectivos destas referências foram: para a Região Sudeste 51,8\%, 57,0\% e 57,6\%, com os Estados do Rio de Janeiro e São Paulo acumulando $42,5 \%, 52,9 \%$ e 56,0\%; para a Região Norte $3,9 \%, 5,0 \%$ e $1,5 \%$.

A concentração da produção científica tendo como referência a localização de instituições da Região Sudeste se acentua ainda mais quando consideramos os percentuais de citações das instituições (Tabela 1), permitindo assim visualizar o grau de envolvimento delas. A Região Sudeste totalizou 76,2\% das citações, com os Estados do Rio de Janeiro e São Paulo sozinhos acumulando $70,9 \%$ e duas grandes instituições, a FIOCRUZ (ENSP, IOC e CICT) e a USP (FSP e FM), concentrando 74 citações, ou seja, 43,0\% de todas as citações de instituições.

Esses resultados apenas refletem processos históricos que vêm contribuindo tanto para a concentração da pesquisa e da produção científica em determinadas Regiões e Estados, como para a tendência, demonstrada no item Escala Espacial de Análise, de a produção de conhecimentos científicos sobre determinados locais raramente considerar suas inter-relações com outros planos ou escalas, que podem incluir desde o município ao Estado até os planos nacional, regional e internacional. Por exemplo, dos 12 textos que envolveram instituições da América Latina, nenhum tratou dos problemas considerando sua inter-relação com o pla- 
no ou escala regional, ou mesmo das inter-relações com outros países vizinhos e com problemas ambientais e de saúde similares. Diminuindo a escala para o plano ou escala nacional, dos nove textos que tiveram o Brasil como unidade de análise, apenas um situou as mudanças no quadro ambiental e de saúde do país na sua inter-relação com as mudanças que vinham ocorrendo no plano ou escala internacional. Regiões do Brasil (dois textos), Estados, municípios ou localidades de municípios foram tratados como unidades espaciais de análise isoladas e não nas suas inter-relações e interdependência com os outros planos ou escalas.

A tendência de concentração das instituições, da produção científica e dos grupos de pesquisas se combina com a tendência de concentração de pesquisas sobre determinados problemas (mercúrio em áreas onde há garimpo de ouro, por exemplo) em determinados municípios e localidades (presença de vetores no Município de Pariquera Açu, em São Paulo, por exemplo), de um modo tal que contribui mais para aumentar os conhecimentos sobre um local do que para o fortalecimento de conhecimentos locais, não levando em consideração na análise suas inter-relações com os outros planos ou escalas. Se pretendermos gerar conhecimentos locais articulados com outros planos ou escalas, a desconcentração da produção científica e aumento da produção científica sobre determinados problemas ou locais que estabeleçam inter-relações com outros planos ou escalas surgem como prioridades.

\section{Aumento da cooperação e promoção de atividades e programas interdisciplinares de pesquisa}

Em relação à cooperação nas atividades de pesquisas, os resultados do item Instituições e Autores são reveladores do quanto ainda é necessário para se avançar neste item em relação às instituições nacionais e internacionais. No plano da cooperação nacional $40,8 \%$ dos textos envolveram apenas uma instituição e há um acúmulo de cerca de $80,0 \%$ se considerarmos até duas instituições (Tabela 2). No plano da cooperação entre instituições de C\&T nacionais e internacionais, o percentual de textos que indicavam a mesma foi de apenas $3,5 \%$, sendo que destes, metade teve como problema ambiental a contaminação por mercúrio oriunda do garimpo e comercialização do ouro. De qualquer modo, deve-se observar que este quadro é positivamente diferente do revelado no estudo realizado por Pellegrini Filho et al. 8 , sobre a produção científica em saúde em seis países da
América Latina no período 1973-1992. Nesse estudo, os autores encontraram que $73,4 \%$ dos textos foram produzidos por autores de uma única instituição, contra 40,8\% encontrado neste estudo. Deve-se, entretanto, notar que os autores trabalharam com um período bem maior do que o estabelecido neste estudo e observaram a tendência de crescimento dos trabalhos em colaboração e um decréscimo dos textos publicados independentemente.

Apesar de neste estudo termos verificado que metade das instituições internacionais é da América Latina, não encontramos nenhum texto demonstrando a cooperação entre estas e instituições nacionais. Isto contribui para acentuar o apontado no item anterior: a ausência de estudos sobre países da região que considerem problemas similares em países vizinhos e/ou sua inter-relação com os mesmos. Este quadro é inverso a uma outra tendência observada por Pellegrini Filho et al. 8, e não verificada neste estudo: a de crescimento do trabalho colaborativo na atividade científica ser acompanhado pela tendência de aumento da colaboração entre pesquisadores de instituições nacionais e internacionais.

Em relação a uma cooperação intersetorial, particularmente entre pelo menos uma instituição de C\&T e uma instituição associada aos serviços, uma prática considerada importante no discurso de constituição do próprio campo da saúde coletiva, foram encontrados 13,9\%. Embora seja de difícil avaliação e não possa ser considerado como único fator, uma hipótese é que este baixo percentual de cooperação intersetorial esteja influenciando a pouca produção de textos orientados para as políticas públicas e tomada de decisões. Outra hipótese possível é que, mais do que o percentual ser considerado baixo, o fator mais importante é que o envolvimento dos serviços na produção científica ocorra muito mais por demanda de pesquisas científicas das instituições de C\&T do que viceversa, contribuindo assim para uma produção científica mais voltada para o diagnóstico do que para a solução dos problemas.

Em relação à interdisciplinaridade os resultados apresentados no item Instituições e Autores propiciam algumas questões. Em primeiro lugar, é importante salientar que o simples fato de haver um grande número de pesquisadores nas publicações não garante, por si só, que uma pesquisa seja interdisciplinar, sendo necessárias mudanças qualitativas nas inter-relações entre as diferentes disciplinas que operam para a construção do conhecimento sobre um problema específico 135. Entretanto, quando há pouco número de pesquisadores envolvidos, 
este pode ser um indicador das limitações do potencial de pesquisas interdisciplinares. No item Instituições e Autores, por exemplo, constatamos que os textos que tiveram até dois autores totalizaram aproximadamente 2/5 dos mesmos e que outros 2/5 envolveram de três a quatro autores (Tabela 3 ). Se combinarmos estes dados com os relativos ao número de instituições envolvidas (Tabela 2), encontraremos uma situação em que 2/5 dos textos envolveram apenas uma instituição e que outros $2 / 5$ envolveram no máximo duas instituições. Combinados, estes dados apontam para um quadro em que pesquisas envolvendo no máximo dois autores em uma instituição são responsáveis por 2/5 do total de textos, podendo constituirse como um indicador de baixíssima cooperação institucional e potencial de pesquisa interdisciplinar. Mesmo ampliando, o quadro que temos é o de pesquisas que envolveram de três a quatro autores em duas instituições no máximo, correspondendo aos outros 2/5 e indicando ainda uma baixa cooperação e potencial de pesquisa interdisciplinar. Totalizando estes dados, temos uma situação em que 4/5 dos textos resultaram de pesquisas que envolveram até quatro autores em no máximo duas instituições, o que certamente ainda é insuficiente para considerarmos que estamos avançando na cooperação entre instituições e na pesquisa interdisciplinar sobre problemas ambientais e de saúde.

Particularmente em relação às instituições de C\&T, chama a atenção a presença daquelas que possuem programas de pós-graduação em saúde coletiva, que estiveram presentes em pouco mais de 50,0\% dos textos. Este dado chama a atenção para a grande responsabilidade destas, já que não são somente instituições de pesquisas, mas também de formação de futuros docentes e pesquisadores que, se continuarem na direção atual, tenderão a reproduzir no futuro a baixa cooperação setorial (C\&T) entre instituições nacionais e internacionais (particularmente da América Latina), e intersetorial (serviços e ONGs) entre instituições nacionais, bem como a baixa atividade interdisciplinar.

\section{Participação popular na fixação}

de prioridades e nas tomadas de decisões

Conforme pudemos observar no item Grupos Populacionais Incluídos no Estudo, para pouco mais de 1/ 4 dos textos a identificação da população alvo do estudo não se aplicava e para quase metade do total de textos a população foi referida de modo bastante geral. Não chegou a totalizar 1/4 o número de textos que identificou um grupo populacional específico em um lugar determinado. Embora esta ausência de identificação e precisão dos grupos populacionais não possa ser considerada como único fator explicativo, é razoável supor que tenha contribuído bastante para o fato de, conforme constatado no item Participação dos Atores Envolvidos nos Problemas, a grande maioria dos textos $(78,3 \%)$ não ter se referido a nenhuma forma de participação. Dos textos que previam alguma forma de participação como importante fator, foram encontradas três estratégias que consideramos dever estar conjugadas, pois só reconhecendo e valorizando o saber local e dos diferentes atores envolvidos, poderemos tanto incluí-los de modo efetivo para uma melhor definição dos problemas e das variáveis, como considerá-los elementos importantes para a gestão e tomadas de decisões sobre as questões ambientais e de saúde.

É bastante provável que o baixo percentual de estudos participativos esteja relacionado, tal como vimos no item Abordagens Teóricometodológicas, à predominância de abordagens que procuraram identificar e quantificar a presença de agentes (químicos, físicos ou biológicos) e que tiveram por base as noções de saúde e ambiente centradas nos aspectos biológicos e biofísicos, acabando por reduzir a compreensão do processo saúde/doença e de alterações ambientais a entidades reais em si mesmas substancialmente separadas das práticas sociais e das experiências humanas. Como observam Funtowicz \& De Marchi 136, não podemos considerar que a prática científica esteja livre de valores, ou seja, descontextualizada, particularmente quando consideramos a produção de um conhecimento científico que tem como objetivo contribuir para a gestão prudente do ambiente e o manejo sustentável do desenvolvimento. Uma produção científica orientada para este objetivo encontra suas justificações nas preocupações sociais prioritárias, devendo contribuir para impulsionar o processo de resolução social de problemas, incluindo a participação e a aprendizagem mútua entre os diferentes atores envolvidos, cientistas e leigos, em vez da busca de "soluções" definitivas ou implementações tecnológicas. Para esses autores, da colocação inicial de um problema até a busca de soluções e definições de estratégias de gestão do mesmo, uma grande variedade de atores, com perspectivas próprias sobre a questão, é envolvida em uma multiplicidade de contextos, de modo que não é apropriado ou frutífero que qualquer uma destas perspectivas, incluindo as dos cientistas e tomadores de decisões, seja dominante ou que exclua as outras 136 . 
Conforme pudemos observar, mais de $3 / 4$ da produção científica analisada neste trabalho não prevê nenhuma forma de participação, desde as fases iniciais de uma pesquisa, quando são colocados os problemas, até os momentos de busca de soluções. Isto certamente se encontra relacionado às questões que trabalhamos nos itens anteriores referentes à predominância de abordagens ainda centradas no diagnóstico, pouco incluindo a busca de soluções, e baseadas em determinadas noções de saúde e ambiente que não incluem a compreensão dos processos históricos, das práticas sociais e das experiências humanas frente aos problemas ambientais e de saúde vivenciados pelos seres humanos. Aponta para a necessidade do desenvolvimento de abordagens que permitam definir os problemas de modo mais contextualizado e que inclua a participação dos diferentes atores sociais envolvidos com os problemas, já se encontrando na literatura exemplos para estudos de avaliação da exposição 137,138 ou que tenham por base a epidemiologia 139 ou análise espacial 140.

\section{Conclusões}

Ao longo deste trabalho demonstramos algumas características da produção científica sobre o tema ambiente na saúde coletiva. O que se verificou foi uma produção científica concentrada, em sua origem, na Região Sudeste (particularmente nos Estados do Rio de Janeiro e São Paulo) em instituições que possuem programas de pós-graduação em saúde coletiva (particularmente FIOCRUZ e USP), com proeminência de alguns autores. Entre outros aspectos, essa concentração pode ter contribuído para a pouca cooperação entre instituições e o reduzido número de pesquisas interdisciplinares. Em termos de definição de problemas e abordagens a serem empregadas, essa produção esteve majoritariamente voltada para o diagnóstico dos problemas, focada nos agentes (físicos, químicos e biológicos), com predominância de abordagens norteadas pelas noções de saúde e ambiente centradas nos aspectos biológicos e biofísicos. O resultado foi uma produção predominantemente não contextualizada nas dimensões sócio-políticas dos problemas, que pouco combinou diagnóstico com busca de soluções e em que a participação dos diferentes atores sociais foi muitíssimo reduzida.

Se aceitarmos a afirmativa de Paim \& Almeida Filho 4 de que a saúde coletiva se constitui como um campo científico interdisciplinar e um âmbito de práticas intersetoriais em que se produzem saberes e conhecimentos sobre o objeto "saúde", como também ações por diversos agentes, especializados e "leigos", dentro e fora das instituições reconhecidas como do "setor saúde", os resultados e discussão presentes neste estudo apontam para uma longa trajetória que ainda deve ser percorrida.

Essa trajetória poderá ter seu tempo reduzido ou ampliado, dependendo das estratégias que possam ser adotadas pelos diferentes atores, dentro e fora do setor saúde, governamentais e não-governamentais, cientistas e leigos. Parte destas estratégias já se encontram presentes na própria definição dos objetivos da primeira área de programas do capítulo 35 da Agenda 21 (Fortalecimento da Base Científica Para o Manejo Sustentável), os quais reproduzimos acrescentando propostas.

O primeiro objetivo é ampliar e fortalecer as capacidades e potenciais científicos em áreas relevantes que envolvem interfaces entre a saúde e as questões ambiente/ambientais. Devem ser ampliadas e fortalecidas principalmente as pesquisas sobre temas relevantes que acabam por ser transversais à maioria dos problemas ambientais e de saúde, sendo estes: (1) o modelo de desenvolvimento, particularmente nos seus aspectos demográficos, de distribuição de riquezas, de utilização de recursos e de políticas macroeconômicas; (2) as desigualdades sócio-ambientais e suas implicações nos processos de destruição/degradação ambiental e de impactos sobre a saúde de determinadas populações ou grupos populacionais; (3) as condições de trabalho formais e informais e suas implicações sobre os processos de destruição/degradação ambiental, bem como sobre a saúde de determinados grupos populacionais; (4) o modelo de educação vigente e suas implicações na conformação de hábitos e atitudes que, desde nível individual, perpetuam e reproduzem o atual modelo de desenvolvimento e suas implicações ambientais e sanitárias; (5) as políticas públicas e suas implicações na constituição de um marco legal e institucional fragmentado e descontínuo no que se refere à proteção e promoção da saúde e de ambientes saudáveis; e (6) os serviços de saúde e seu papel no diagnóstico, vigilância e promoção da saúde ambiental. O fortalecimento de pesquisas sobre estes temas não deve ocorrer em detrimento de outros como os relacionados à poluição e ao controle de vetores, mas aponta para abordagens mais integradas e contextualizadas dos problemas ambientais e de saúde.

O segundo objetivo é o de produzir conhecimentos científicos orientados para a formu- 
lação de políticas públicas e a tomada de decisões, utilizando a abordagem da precaução. É necessário que ocorram em todos os níveis investimentos maciços no sentido de reorientar as pesquisas, de modo que se inverta o quadro atual, passando a maior parcela da produção científica sobre diagnósticos de problemas a incorporar a proposição de políticas públicas e estratégias para a gestão dos mesmos, utilizando a abordagem da precaução como norteadora de ambas. Para que esse objetivo possa ser cumprido, recorremos a dois outros capítulos da Agenda 21, o 8 (Integração Entre Meio Ambiente e Desenvolvimento na Tomada de Decisões) e o 40 (Informação Para a Tomada de Decisões), que devem nortear a produção científica. Ambos os capítulos apontam para a necessidade de uma produção científica que integre propostas de políticas públicas e estratégias de gestões que integrem meio ambiente, saúde, sustentabilidade e gestão prudente nas tomadas de decisões.

O terceiro objetivo é o de gerar conhecimentos locais, considerando as relações com os planos nacional, regional e internacional. Particularmente em relação a esse objetivo é evidente e urgente a necessidade de investimentos que sejam capazes de a médio e longo prazos mudarem o quadro atual, particularmente em relação à Região Norte. Em relação a esse objetivo, instituições como a ABRASCO, o CNPq, a CAPES, o Ministério da Saúde, assim como as instituições de amparo à pesquisa e de ensino de graduação e pós-graduação, deveriam conjuntamente formular e propor uma estratégia de médio e longo prazos para a ampliação e fortalecimento das capacidades de pesquisas sobre as interfaces entre as questões ambiente/ambientais, bem como a criação de programas de pós-graduação em saúde coletiva, tendo em vista ser a única região que não possuí algum. A desconcentração e desenvolvimento das capacidades científicas locais e regionais devem estar orientados para a geração de conhecimentos mais contextualizados.

O quarto objetivo é aumentar a cooperação e promoção de atividades e programas interdisciplinares de pesquisa. Para esse objetivo, tomamos como exemplo Masera 141, que procura definir os requisitos para uma ciência ambiental e que acreditamos podem ser estendidos às questões abordadas neste trabalho. Para este autor, os problemas ambientais devem ser tratados de forma sistêmica e numa perspectiva interdisciplinar e integrada que envolva a complexa inter-relação entre as questões e problemas ambientais, sociais e econômicos, ao que acrescentaríamos os problemas de saúde, possuindo a formação de alunos de graduação e pós-graduação um papel fundamental nesta direção. Assim, podemos considerar que políticas públicas referentes ao ensino de graduação e pós-graduação, bem como ao financiamento de pesquisas que estimulem a cooperação entre instituições de ensino superior, programas de pós-graduação e grupos de pesquisas numa perspectiva interdisciplinar são fundamentais.

O quinto objetivo é o de ampliar e fortalecer a participação popular na fixação de prioridades e nas tomadas de decisões. Se queremos efetivamente conformar uma ciência orientada para o desenvolvimento sustentável do ambiente e da saúde coletiva, não se pode esquecer que, como afirmam Funtowicz \& De Marchi 136, o objetivo do âmbito científico, neste novo contexto, é o de impulsionar o processo de resolução social de problemas, incluindo a participação e a aprendizagem mútua entre os diferentes atores sociais envolvidos. Isto implica, como observam Paim \& Almeida Filho 4, que o enfrentamento dos desafios da saúde com eqüidade envolva a constituição de sujeitos comprometidos com novas utopias, dentre as quais destacamos a de um mundo sustentável no que se refere aos aspectos ambientais e de saúde, que possam ser elevados ao patamar de parceiros e cidadãos. Assim, podemos também considerar que políticas públicas referentes à formação desde a graduação até a pós-graduação, bem como ao financiamento de pesquisas, que estimulem o desenvolvimento de abordagens participativas para a compreensão e busca de soluções dos problemas ambientais e de saúde como fundamental.

Para que esses objetivos possam ser atendidos, concluímos que talvez o primeiro passo seja configurar uma noção de saúde e ambiente na perspectiva da saúde coletiva e que contribua para conformar uma ciência orientada para a sustentabilidade do ambiente e da saúde. Objetivando contribuir nesta direção, consideramos que o tema saúde e ambiente deveria ser definido na saúde coletiva como o que trata dos processos em que as mudanças nos ambientes (dos níveis local ao global, incluindo suas dimensões sociais, políticas, econômicas, culturais e biofísicas) geram conseqüências sobre a sustentabilidade do ambiente (ameaçando ou promovendo a integridade sócio-ecológica) e da saúde humana. 


\section{Resumo}

Embora existam poucos estudos sobre a incorporação do tema ambiente na saúde coletiva, há indicações que apontam para a institucionalização deste tema nas linhas de pesquisas dos grupos de pesquisas e programas de pós-graduação, bem como na formação de pesquisadores qualificados, se consolidando na produção científica. Este estudo tem como objetivo compreender como este tema vem sendo incorporado na saúde coletiva, fornecendo assim subsídios para a conformação de uma ciência orientada para o desenvolvimento sustentável do ambiente e da saúde coletiva. Para atingir este objetivo foi realizado um levantamento e análise da produção científica sobre o tema ambiente em quatro das principais revistas científicas nacionais, no período 1992-2002, tendo como referência a primeira área de programa do capítulo da Agenda 21 dedicado à ciência para o desenvolvimento sustentável. Os resultados apontam para uma produção científica concentrada nas instituições da Região Sudeste; centrada em noções biológicas da saúde e biofísicas do ambiente; predominando os estudos de diagnóstico, com poucos incorporando a busca de soluções e pequeno número de estudos em que se prevê a participação dos diferentes atores envolvidos com os problemas ambientais.

Saúde Ambiental; Meio Ambiente e Saúde Pública; Literatura de Revisão [Tipo de Publicação]

\section{Agradecimentos}

Gostaria de agradecer a Adauto José Gonçalves de Araújo, Christovam de Castro Barcellos, Marcelo Firpo de Souza Porto e Paulo Chagastelles Sabroza, que com seus comentários e sugestões permitiram que refletisse e trabalhasse ainda mais neste artigo.

\section{Referências}

1. Frank DJ, Hironaka A, Evan S. Enviromentalism as a global institution. Am Sociol Rev 2000; 65:122-7.

2. United Nations Environmental Program. Integrating environment and development: 1972-2002. In: Global Environmental Outlook 3 - Past, Present and Future Perspectives. London: Earthscan Publications; 2002. p. 1-27.

3. Macnaghten P, Urry J. Contested natures. London: Sage Publications; 1998.

4. Paim JS, Almeida Filho N. A crise da saúde pública e a utopia da saúde coletiva. Salvador: Casa da Qualidade Editora; 2000.

5. Barata RB, Goldbaum M. Perfil dos pesquisadores com bolsa de produtividade em pesquisa do $\mathrm{CNPq}$ da área de saúde coletiva. Cad Saúde Pública 2003; 19:1863-76.

6. Freitas CM. Problemas ambientais, saúde coletiva e ciências sociais. Ciênc Saúde Coletiva 2003; 8:137-50.

7. Viacava F, Ramos C. Difusão da produção científica dos cursos de pós-graduação em saúde coletiva. Ciênc Saúde Coletiva 1997; 2:142-53.

8. Pellegrini Filho A, Goldbaum, M, Silvi J. Production of scientific articles on health in six Latin American countries, 1973-1992. Rev Panam Salud Publica 1997; 2:121-9.

9. Guimarães R, Lourenço R, Cosac S. A pesquisa em epidemiologia no Brasil. Rev Saúde Pública 2001; 35:321-40.

10. Guimarães RP. La sostenibilidad del desarrollo entre Rio-92 y Johannesburgo 2002: eramos felices y no sabiamos. Ambient Soc 2001; 9:1-20.

11. Minayo MCS, Freitas CM, Rozemberg B, Mendes RL, Porto, MFS, Soares M. O programa institucional sobre saúde e ambiente no processo de desenvolvimento da Fundação Oswaldo Cruz. An Acad Bras Ciênc 1999; 71:279-88.

12. Fundação Nacional de Saúde. Projeto Vigisus estruturação do Sistema Nacional de Vigilância em Saúde. Brasília: Fundação Nacional de Saúde, Ministério da Saúde; 1998.

13. Sabroza PC, Leal MC, Buss PM. A ética do desenvolvimento e a proteção às condições de saúde. Cad Saúde Pública 1992; 8:88-95.

14. Mohr A, Schall VT. Rumos da educação em saúde no Brasil e sua relação com a educação ambiental. Cad Saúde Pública 1992; 8:199-203.

15. Cordellier R, Degallier N. Environment, arbovirus transmission and control of epidemics. Cad Saúde Pública 1992; 8:249-53.

16. Bos R. New approaches to disease vector control in the context of sustainable development. Cad Saúde Pública 1992; 8:240-8.

17. Duchiade MP. Poluição do ar e doenças respiratórias: uma revisão. Cad Saúde Pública 1992; 8:311-30.

18. Coura JR. Endemias e meio ambiente no século XXI. Cad Saúde Pública 1992; 8:335-41.

19. D'Ambrosio U. Obsolescência institucional e degradação ambiental e social. Cad Saúde Pública 1992; 8:466-9.

20. Boischio AAP, Barbosa A. Exposição ao mercúrio orgânico em populações ribeirinhas do Alto Madeira, Rondônia, 1991: resultados preliminares. Cad Saúde Pública 1993; 9:155-60. 
21. Fearnside PM. Migração, colonização e meio ambiente: o potencial dos ecossistemas amazônicas. Cad Saúde Pública 1993; 9:448-57.

22. Wanderley DMV. Chagas' disease: the rural environment and vector control in the state of São Paulo, Brazil. Cad Saúde Pública 1993; 9:466-76.

23. Gomez CM, Carvalho SMTM. Social inequalities, labor, and health. Cad Saúde Pública 1993; 9:498503.

24. Gajate PP, Bottazzi MV, Pietrokovsky SM, Wisnivesky-Colli C. Relação entre Triatoma infestans, aves domésticas e o homem num povoado de Santiago del Estero, Argentina. Cad Saúde Pública 1994; 10:53-7.

25. Schall VT. Environmental and health education for shcool-age children: a transdisciplinary approach. Cad Saúde Pública 1994; 10:259-63.

26. Archer RMB, Moretto E. Ocorrência de Vibrio parahaemolyticus em mexilhões (Perna perna, Linnaeus, 1758) de banco natural do litoral do município de Palhoça, Santa Catarina, Brasil. Cad Saúde Pública 1994; 10:379-86.

27. Kloetzel K, Chieffi PP, Carilho FJ. Environmental intervention as a tool for control o schitosomiasis: suggestions from a field study in Northeast Brazil. Cad Saúde Pública 1994; 10 Suppl:337-44.

28. Ferreira JA. Resíduos sólidos e lixo hospitalar: uma discussão ética. Cad Saúde Pública 1995; 11:31420.

29. Coura-Filho P, Farah MWC, Rezende FF, Lamartine SS, Carvalho OS, Katz N. Determinantes ambientais e sociais da esquistossomose mansoni em Ravena, Minas Gerais, Brasil. Cad Saúde Pública 1995; 11:254-65.

30. Santos EO, Loureiro ECB, Jesus IM, Brabo E, Silva RSU, Soares MCP. Diagnóstico das condições de saúde de uma comunidade garimpeira na Região do Rio Tapajós, Itaituba, Pará, Brasil, 1992. Cad Saúde Pública 1995; 10:212-25.

31. Câmara VM, Silva AP, Pivetta F, Perez MA, Lima MIM, Filhote MIF, et al. Estudo dos níveis de exposição e efeitos à saúde por mercúrio metálico em uma população urbana de Poconé, Mato Grosso, Brasil. Cad Saúde Pública 1996; 12:69-77.

32. Câmara VM, Filhote MIF, Lima MIM, Alheira FV, Martins MS, Dantas TO, et al. Metodologia para prevenir exposição ao mercúrio em adolescentes de garimpos de ouro em Mariana, Minas Gerais, Brasil. Cad Saúde Pública 1996; 12:149-58.

33. Barcellos C, Bastos FI. Geoprocessamento, ambiente e saúde: uma união possível? Cad Saúde Pública 1996; 12:389-97.

34. Cordeiro R, Lima Filho, EC, Salgado PET. Reajustando o limite de tolerância biológica aplicado à plumbemia no Brasil. Cad Saúde Pública 1996; 12:455-63.

35. Sisinno CLS, Moreira JC. Avaliação da contaminação e poluição ambiental na área de influência do aterro controlado do Morro do Céu, Niterói, Brasil. Cad Saúde Pública 1996; 12:515-23.

36. Silva ER, Schramm FR. A questão ecológica: entre a ciência e a ideologia/utopia de uma época. Cad Saúde Pública 1997; 13:355-82.

37. Nogueira F, Nascimento OC, Silva EC, Junk W. Mercúrio total em cabelos: uma contribuição para se avaliar o nível de exposição em Poconé, Ma- to Grosso, Brasil. Cad Saúde Pública 1997; 13:601-9.

38. Kuriyama GS, Moreira JC, Silva CRS. Exposição ocupacional ao dióxido de nitrogênio $\left(\mathrm{NO}_{2}\right)$ em policiais de trânsito na cidade do Rio de Janeiro. Cad Saúde Pública 1997; 13:677-83.

39. Gomes-Carneiro MR, Ribeiro-Pinto LF, Paumgartten FJR. Fatores de risco ambientais para o câncer gástrico: a visão do toxicologista. Cad Saúde Pública 1997; 13 Suppl 1:27-38.

40. Porto MFS, Freitas CM. Análise de riscos tecnológicos ambientais: perspectivas para o campo da saúde do trabalhador. Cad Saúde Pública 1997; 13 Suppl 2:59-72.

41. Colaço W, Silva Filho SV, Rodrigues DP, Hofer E. Vibrio cholerae $\mathrm{O}_{1}$ em amostras de ambientes aquáticos e de alimentos analisados no Estado de Pernambuco, Brasil. Cad Saúde Pública 1998; 14:465-71.

42. Peiter P, Tobar C. Poluição do ar e condições de vida: uma análise geográfica de riscos à saúde em Volta Redonda, Rio de Janeiro, Brasil. Cad Saúde Pública 1998; 14:473-85.

43. Barcellos C, Coutinho K, Pina MF, Magalhães MMAF, Paola JCMD, Santos SM. Inter-relacionamento de dados ambientais e de saúde: análise de risco à saúde aplicada ao abastecimento de água no Rio de Janeiro utilizando sistemas de informações geográficas. Cad Saúde Pública 1998; 14:597-605.

44. Matos E, Vilensky M, Boffetta P. Environmental and occupational cancer in Argentina: a case-control lung cancer study. Cad Saúde Pública 1998; 14 Suppl 3:77-86.

45. Franco Netto G. On the need to assess cancer risk in populations environmentally and occupationally exposed to virus and chemical agents in developing countries. Cad Saúde Pública 1998; 14 Suppl 3:87-98.

46. Olaya-Contreras P, Rodríguez-Villamil J, PossoValencia HJ, Cortez JE. Organochlorine exposure and breast cancer risk in colombian women. Cad Saúde Pública 1998; 14 Suppl 3:125-32.

47. Mendonça GAS. Measuring exposure to organochlorinated pesticides. Cad Saúde Pública 1998; 14 Suppl 3:177-9.

48. Ferreccio C, Psych CG, Stat VM, Gredis GM, Sancha AM. Lung cancer and arsenic exposure in drinking water: a case-control study in Northern Chile. Cad Saúde Pública 1998; 14 Suppl 3:193-8.

49. Araujo UC, Pivetta FR, Moreira JC. Avaliação da exposição ocupacional ao chumbo: proposta de uma estratégia de monitoramento para prevenção dos efeitos clínicos e subclínicos. Cad Saúde Pública 1999; 15:123-32.

50. Engstrom EM, Anjos LA. Déficit estatural nas crianças brasileiras: relação com condições sócioambientais e estado nutricional materno. Cad Saúde Pública 1999; 15:559-67.

51. Meyer A, Sarcinelli PN, Moreira JC. Estarão alguns grupos populacionais brasileiros sujeitos à ação de disruptores endócrinos? Cad Saúde Pública 1999; 15:845-50.

52. Teodoro U, Kühl JB, Santos DR, Santos ES. Impacto de alterações ambientais na ecologia de flebotomíneos no Sul do Brasil. Cad Saúde Pública 1999; 15:901-6. 
53. Grynszpan D. Educação em saúde e educação ambiental: uma experiência integradora. Cad Saúde Pública 1999; 15 Suppl 2:133-8.

54. André PA, Braga ALF, Lin CA, Conceição GMS, Pereira LAA, Miraglia SGK, et al. Environmental epidemiology applied to urban atmospheric pollution: a contribution from the Experimental Air Pollution Laboratory (LPAE). Cad Saúde Pública 2000; 16:619-28.

55. Koifman S. Geração e transmissão da energia elétrica: impacto sobre os povos indígenas no Brasil. Cad Saúde Pública 2001; 17:413-23.

56. Pivetta F, Machado JMH, Araujo UC, Moreira MFR, Apostoli P. Monitoramento biológico: conceitos e aplicações em saúde pública. Cad Saúde Pública 2001; 17:545-54.

57. Quiterio SL, Silva CRS, Vaitsman DS, Martinhon PT, Moreira MFR, Araujo UC, et al. Uso da poeira e do ar como indicadores de contaminação ambiental em áreas circunvizinhas a uma fonte de emissão estacionária de chumbo. Cad Saúde Pública 2001; 17:501-8.

58. Damborsky MP, Bar ME, Oscherov EB. Detección de triatominos (Hemiptera: Reduviidae) en ambientes domésticos y extradomésticos. Corrientes, Argentina. Cad Saúde Pública 2001; 17:843-9.

59. Braga C, Ximenes RA, Albuquerque MFPM, Souza WV, Miranda J, Brayner F, et al. Avaliação de indicador sócio-ambiental utilizado no rastreamento de áreas de transmissão de filariose linfática em espaços urbanos. Cad Saúde Pública 2001; 17: 1211-8.

60. Barcellos C, Sabroza PC. The place behinde the case: leptospirosis risks and associated environmental conditions in a flood-related outbreak in Rio de Janeiro. Cad Saúde Pública 2001; 17 Suppl 1:59-67.

61. Dias JCP. Doença de chagas, ambiente e participação do estado. Cad Saúde Pública 2001; 17 Suppl 1:165-9.

62. Freitas CM, Porto MFS, Moreira JC, Pivetta F, Machado JMH, Freitas NBB, et al. Segurança química, saúde e ambiente - perspectivas para governança no contexto brasileiro. Cad Saúde Pública 2002; 18:249-56.

63. Cocco P. On the rumors about the silent spring: review of the scientific evidence linking occupational and environmental pesticide exposure to endocrine disruption health effects. Cad Saúde Pública 2002; 18:379-402.

64. Jarrell J. Rationale for the study of the human sex ratio in population studies of polluted environments. Cad Saúde Pública 2002; 18:429-34.

65. Fernandez MA, Limaverde AM, Castro IB, Almeida ACM, Wagener ALR. Occurrence of imposex in Thais haemastoma: possible evidence of environmental contamination derived from organotin compounds in Rio de Janeiro and Fortaleza, Brazil. Cad Saúde Pública 2002; 18:463-76.

66. Rosa MLG, Hortale VA. Óbitos perinatais evitáveis e ambiente externo ao sistema de assistência: estudo de caso em município da Região Metropolitana do Rio de Janeiro. Cad Saúde Pública 2002; 18:623-31

67. Nogueira JMR, Rodrigues DP, Hofer E. Viabilidade de Vibrio cholerae $\mathrm{O}_{1}$ em diferentes tipos de águas em condições experimentais. Cad Saúde Pública 2002; 18:1339-45.

68. Silva ACN, Bernardes RS, Moraes LRS, Reis JDP. Critérios adotados para seleção de indicadores de contaminação ambiental relacionados aos resíduos sólidos de serviços de saúde: uma proposta de avaliação. Cad Saúde Pública 2002; 18:1401-9.

69. Gazzinelli MF, Gazzinelli A, Santos RV, Gonçalves LAO. A interdição da doença: uma construção cultural da esquistossomose em área endêmica, $\mathrm{Mi}$ nas Gerais, Brasil. Cad Saúde Pública 2002; 18: 1629-38.

70. Soares SRA, Bernardes RS, Cordeiro Netto OM. Relações entre saneamento, saúde pública e meio ambiente: elementos para formulação de um modelo de planejamento em saneamento. Cad Saúde Pública 2002; 18:1713-4.

71. Pinto TJA, Saito T. Esterilização por óxido de etileno. I. Influência do meio de esporulação na resistência dos esporos de Bacillus subtilis var. niger. Rev Saúde Pública 1992; 26:379-83.

72. Pinto TJA, Saito T. Esterilização por óxido de etileno. II. Influência de corpos de prova no desempenho de monitores biológicos e sua avaliação. Rev Saúde Pública 1992; 26:384-91.

73. Santos UP, Rumel D, Martarello NA, Ferreira CSW, Matos MP. Síndrome dos edifícios doentes em bancários. Rev Saúde Pública 1992; 26:400-4.

74. Forattini OP, Kakitani I, Massad E, Gomes AC. Studies on mosquitoes (Diptera: Culicidae) and anthropic environment. 1 - Parity of blood seeking Anopheles (Kerteszia) in South-Eastern Brazil. Rev Saúde Pública 1993; 27:1-8.

75. Forattini OP, Kakitani I, Massad E, Marucci D. Studies on mosquitoes (Diptera: Culicidae) and anthropic environment. 2 - Immature stages research at a rice irrigation system location in SouthEastern Brazil. Rev Saúde Pública 1993; 27:227-36.

76. Forattini OP, Kakitani I, Massad E, Marucci D. 1993. Studies on mosquitoes (Diptera: Culicidae) and anthropic environment. 3 - Survey of adult stages at the rice irrigation system and the emergence of Anopheles albitarsis in South-Eastern Brazil. Rev Saúde Pública 1993; 27:313-25.

77. Forattini OP, Kakitani I, Massad E, Marucci D. Studies on mosquitoes (Diptera: Culicidae) and anthropic environment. 4 - Survey of adult and synanthropic in South-Eastern, Brazil. Rev Saúde Pública 1993; 27:398-411.

78. Almeida LP, Martins LFS, Brod CS, Germano PML Levantamento soroepidemiológico de leptospirose em trabalhadores do serviço de saneamento ambiental em localidade urbana da Região Sul do Brasil. Rev Saúde Pública 1994; 28:76-81.

79. Teodoro U, Guilherme ALF, Lozovei, La Salvia Filho V, Sampaio AA, Spinosa RP, et al. Mosquitos de ambientes peri e extradomiciliares na Região Sul do Brasil. Rev Saúde Pública 1994; 28:107-15.

80. Zuñiga CG, Peña PH, Guerrero CO, Fernández RZ, Burgoa-Santos C. Evaluación económica y toma de decisiones en salud ambiental. Rev Saúde Pública 1994; 28:153-66.

81. Akerman M, Stephens C, Campanario P, Maia PB. Saúde e meio ambiente: uma análise de diferenciais intra-urbanos enfocando o Município de São Paulo, Brasil. Rev Saúde Pública 1994; 28:320-5. 
82. Forattini OP, Kakitani I, Massad E, Marucci D. Studies on mosquitoes (Diptera: Culicidae) and anthropic environment. 5 - Breeding of Anopheles albitarsis in flooded rice fields in South-Eastern, Brazil. Rev Saúde Pública 1994; 28:329-31.

83. Forattini OP, Kakitani I, Massad E, Marucci D. 1994. Studies on mosquitoes (Diptera: Culicidae) and anthropic environment. 6 - Breeding in empty conditions of rice fields in South-Eastern, Brazil. Rev Saúde Pública 1994; 28:95-9.

84. Forattini OP, Kakitani I, Massad E, Marucci D. Studies on mosquitoes (Diptera: Culicidae) and anthropic environment. 7 - Behaviour of adults Nyssorhynchus anophelines with special reference to Anopheles albitarsis s.l. in South-Eastern Brazil. Rev Saúde Pública 1995; 29:20-6.

85. Forattini OP, Sallum MAM, Kakitani I, Massad E, Marucci D. Studies on mosquitoes (Diptera: Culicidae) and anthropic environment. 8 - Survey of adults behaviour of Spissipes Section species of Culex (Melanoconion) in South-Eastern Brazil. Rev Saúde Pública 1995; 29:100-7.

86. Forattini OP, Kakitani I, Massad, Marucci D. Studies on mosquitoes (Diptera: Culicidae) and anthropic environment. 9 - Synanthropy and epidemiological vector role of Aedes scapularis in South-Easter Brazil. Rev Saúde Pública 1995; 29: 199-207.

87. Oliveira RM, Brilhante OM, Moreira JC, Miranda AC. Contaminação por hexaclorociclohexanos em área urbana da Região Sudeste do Brasil. Rev Saúde Pública 1995; 29:228-33.

88. Forattini OP, Kakitani I, Massad E, Marucci D. Studies on mosquitoes (Diptera: Culicidae) and anthropic environment. 10 - Survey of adult behaviour of Culex nigripalpus and other species of Culex (Culex) in South-Easter Brazil. Rev Saúde Pública 1995; 29:271-8.

89. Freitas CM, Porto MFS, Gomez CM. Acidentes químicos ampliados - um desafio para a saúde pública. Rev Saúde Pública 1995; 29:503-14.

90. Forattini OP, Kakitani I, Massad E, Marucci D. Studies on mosquitoes (Diptera: Culicidae) and anthropic environment. 11 - Biting activity and blood-seeking parity of Anopheles (Kerteszia) in South-Easter Brazil. Rev Saúde Pública 1996; 30: 107-14.

91. Forattini OP, Kakitani I, Massad E, Marucci D. Studies on mosquitoes (Diptera: Culicidae) and anthropic environment. 12 - Host-seeking behaviour of Anopheles albitarsis s.l. in South-Easter Brazil. Rev Saúde Pública; 30:299-303.

92. Akerman M, Campanario P, Maia PB. Saúde e meio ambiente: análise de diferenciais intra-urbanos, município de São Paulo, Brasil. Rev Saúde Pública 1996; 30:372-82.

93. Miranda C, Massa JL, Marques CCA. Análise da ocorrência de leishmaniose tegumentar americana através de imagem obtida por sensoriamento remoto orbital em localidade urbana da Região Sudeste do Brasil. Rev Saúde Pública 1996; 30: 433-7.

94. Okada IA, Sakuma AM, Maio FD, Dovidauskas S, Zenebon O. Avaliação dos níveis de chumbo e cádmio em leite em decorrência de contaminação ambiental na Região do Vale do Paraíba, Su- deste do Brasil. Rev Saúde Pública 1997; 31:140-3.

95. Forattini OP, Kakitani I, Sallum MAM, Rezende L. Produtividade de criadouro de Aedes albopictus em ambiente urbano. Rev Saúde Pública 1997; 31:545-55

96. Lima RC, Victora CG, Dall'Agnol MM, Facchini LA, Fassa AG. Percepção de exposição a cargas de trabalho e riscos de acidentes em Pelotas, RS (Brasil). Rev Saúde Pública 1999; 33:137-46.

97. Faria MAM, Almeida JWR, Zanetta DMT. Mortalidade por câncer na região urbano-industrial da Baixada Santista, SP (Brasil). Rev Saúde Pública 1999; 33:255-61.

98. Assunção JV, Pesquero CR. Dioxinas e furanos: origens e riscos. Rev Saúde Pública 1999; 33:523-30.

99. Pereira EDB, Torres L, Macêdo J, Medeira MC. Efeitos do fumo ambiental no trato respiratório inferior de crianças com até 5 anos de idade. Rev Saúde Pública 2000; 34:39-43.

100. Araújo ACP, Nogueira DP, Augusto LGS. Impacto dos praguicidas na saúde: estudo na cultura de tomate. Rev Saúde Pública 2000; 34:309-13.

101. Monteiro CA, Nazário CL. Evolução de condicionantes ambientais da saúde na infância na Cidade de São Paulo. Rev Saúde Pública 2000; 34 Suppl 6:13-8.

102. Queiróz MF, Maciel RH. Condições de trabalho e automação: o caso do soprador da indústria vidreira. Rev Saúde Pública 2001; 35:1-9.

103. Leite JCL, Lavínia SF. Defeitos congênitos em uma região de mineração de carvão. Rev Saúde Pública 2001; 35:136-41.

104. Marques GRA, Santos RC, Forattini OP. Aedes albopictus em bromélias de ambiente antrópico no Estado de São Paulo, Brasil. Rev Saúde Pública 2001; 35:243-8.

105. Oliveira LM, Stein N, Sanseverino MTV, Vargas VMF, Fachel JMG, Schüller L. Riscos reprodutivos em região próxima ao pólo petroquímico de Triunfo no Sul do Brasil. Rev Saúde Pública 2002; 36:81-7.

106. Barquera S, Rico-Mendez FG, Tovar V. Metodologia na pesquisa epidemiológica de doenças respiratórias e poluição ambiental. Rev Saúde Pública 2002; 36:107-13.

107. Calado DC, Silva MAN. Avaliação da influência da temperatura sobre o desenvolvimento de Aedes albopictus. Rev Saúde Pública 2002; 36:173-9.

108. Moraes DSL, Jordão BQ. Degradação de recursos hídricos e seus efeitos sobre a saúde humana. Rev Saúde Pública 2002; 36:370-4.

109. Egwari L, Aboaba OO. Impacto ambiental sobre a qualidade bacteriológica do abastecimento domiciliar de água em Lagos, Nigéria. Rev Saúde Pública 2002; 36:513-20.

110. Chiesa AM, Westphal MF, Kashiwagi NM. Geoprocessamento e a promoção da saúde: desigualdades sociais e ambientais em São Paulo. Rev Saúde Pública 2002; 36:559-67.

111. Rocha R, Porto M, Morelli MYG, Maestá N, Waib PH, Burini RC. Efeito de estresse ambiental sobre a pressão arterial de trabalhadores. Rev Saúde Pública 2002; 36:568-75.

112. Duval G. Salud y ambiente en el proceso de desarollo. Ciênc Saúde Coletiva 1998; 3:7-16

113. Porto MFS. Saúde, ambiente e desenvolvimento: 
reflexões sobre a experiência da COPASAD - Conferência Pan-americana de Saúde e Ambiente no Contexto do Desenvolvimento Sustentável. Ciênc Saúde Coletiva 1998; 3:33-46.

114. Tambellini AT, Câmara VM. A temática saúde e ambiente no processo de desenvolvimento do campo da saúde coletiva: aspectos históricos, conceituais e metodológicos. Ciênc Saúde Coletiva $1998 ; 3: 47-59$.

115. Franco TE, Druck G. Padrões de industrialização, riscos e meio ambiente. Ciênc Saúde Coletiva $1998 ; 3: 61-72$

116. Augusto LGS, Freitas CM. O princípio da precaução no uso de indicadores de riscos químicos ambientais em saúde do trabalhador. Ciênc Saúde Coletiva 1998; 3:85-95.

117. Barcellos C, Machado JMH. A organização espacial condiciona as relações entre o ambiente e saúde: o exemplo da exposição ao mercúrio em uma fábrica de lâmpadas fluorescentes. Ciênc Saúde Coletiva 1998; 3:103-13.

118. Soares MS, Silva CLPAC, Barreto MGM, Baptista DF, Borges DA. Solução de problemas em saúde e ambiente: ciência pós-normal e comunidade ampliada de pares em um município brasileiro de pequeno porte. Ciênc Saúde Coletiva 1998; 3:11523.

119. Rigotto RM, Almeida VL. Capacitando profissionais em saúde, trabalho e meio ambiente. Ciênc Saúde Coletiva 1998; 3:163-70.

120. Duchiade MP. Epidemiologia ambiental: uma (antiga) ciência nova? Inf Epidemiol SUS 1992; 1:29-50.

121. Soares Filho BS, Sawyer DO. Correlatos ambientais da distribuição espacial da malária em municípios endêmicos do Norte do Estado do Mato Grosso. Inf Epidemiol SUS 1996; 5:47-57.

122. Barcellos C, Santos SM. Colocando dados no mapa: a escolha da unidade espacial de agregação e integração de bases de dados em saúde e ambiente através do geoprocessamento. Inf Epidemiol SUS 1997; 6:21-9.

123. Câmara VM, Silva AP, Cancio JA. Notas para a constituição de um programa de vigilância ambiental dos riscos e efeitos da exposição do mercúrio metálico em áreas de produção de ouro. Inf Epidemiol SUS 1998; 7:35-44.

124. Tavares LMSA, Tavares ED. Incidência, distribuição geográfica e aspectos ambientais das áreas endêmicas da leishmaniose visceral em Sergipe. Inf Epidemiol SUS 1999; 8:47-52.

125. Maciel Filho AA, Góes Jr. CD, Cancio JA, Oliveira ML, Costa SS. Indicadores de vigilância ambiental em saúde. Inf Epidemiol SUS 1999; 8:59-66.

126. Freitas CM, Amorin AE. Vigilância ambiental em saúde de acidentes químicos ampliados no transporte rodoviário de cargas perigosas. Inf Epidemiol SUS 2001; 10:31-42.

127. Freitas CM. Avaliação de riscos como ferramenta para a vigilância ambiental em saúde. Inf Epidemiol SUS 2002; 11:227-39.

128. Organización Panamericana de la Salud. Nuestro planeta, nuestra salud - Informe de la Comisión de Salud y Medio Ambiente de la OMS. Washington DC: Organización Panamericana de la Salud; 1993.
129. Arredondo A. Análisis y reflexión sobre modelos teóricos del processo salud-enfermedad. Cad Saúde Pública 1992; 8:254-61.

130. Toledo MA. Saúde, ambiente, desenvolvimento e ecossistemas: um levantamento da produção na pós-graduação da ENSP/FIOCRUZ na década de 1990 [Dissertação de Mestrado]. Rio de Janeiro: Escola Nacional de Saúde Pública, Fundação Oswaldo Cruz; 2002.

131. World Resources Institute. World resources 1998 99 - environmental change and human health. Oxford: Oxford University Press; 1998.

132. Rodríguez D, Del Castillo P, Aguilar C. Glosario de términos en salud ambiental: con especial énfasis en los efectos en salud relacionados con las sustancias químicas. México DF: Organización Panamericana de Salud; 1990.

133. Organização Pan-Americana da Saúde, Organização Mundial da Saúde. Programa marco de atenção ao meio ambiente. Brasília: Organização Pan-Americana da Saúde, Organização Mundial da Saúde; 1998.

134. Rummler G, Spinola AWP. Identificação e procedência de periódicos nacionais referentes à temática de saúde pública ou saúde coletiva, editados entre 1998 e 2003. Cad Saúde Pública 2004; 20:1041-9.

135. Jollivet M, Pavé A. The environment: questions and prospects for research. Environment 1992; $6: 5-27$

136. Funtowicz SO, De Marchi B. Ciencia posnormal, complejidad reflexiva y sustentabilidad. In: Leff E, editor. La complejidad ambiental. México DF: Siglo XXI; 2000. p. 54-84.

137. O’Brien M. Making better environmental decisions - an alternative to risk assessment. Cambridge: The MIT Press; 2000.

138. Bailey P, Yarley S, Forrester J. Involving the public in local air pollution assessment: a citizen participation case study. International Journal of Environmental and Pollution 1999; 11:290-303.

139. Brown P. Popular epidemiology, toxic waste and social movements. In: Gabe J, editor. Sociology of health and illness monographs - medicine, health and risk. Oxford: Blackwell Publishers; 1995. p. 91-112.

140. Cinderby S. Geographic information systems (GIS) for participation: the future of environmental GIS? International Journal of Environmental and Pollution 1999; 11:304-15.

141. Masera OR [Editorial]. Environmental science and policy in the next century: a personal view of future challenges. Environmental Science \& Policy 2000; 3:59-60.

Recebido em 21/Set/2004

Versão final reapresentada em 10/Dez/2004

Aprovado em 06/Jan/2005 